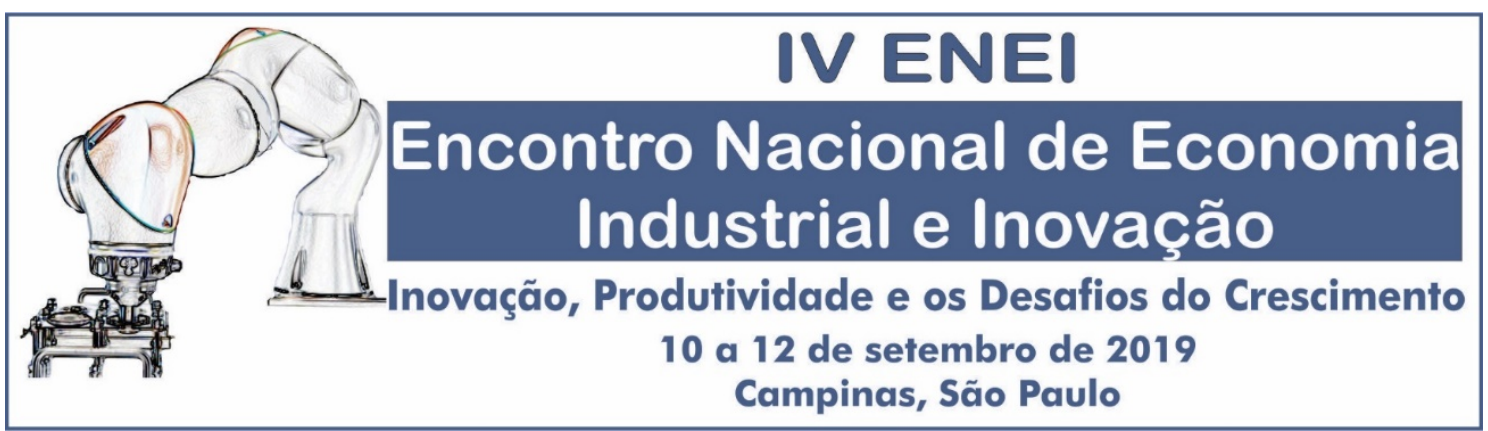

\title{
Pesquisa \& Desenvolvimento setorial direta e indireta da economia brasileira
}

\author{
Paulo César Morceiro (FEA-USP) ${ }^{\mathrm{a}}$ \\ Milene Simone Tessarin (FEA-USP) ${ }^{\mathrm{a}}$ \\ Joaquim José Martins Guilhoto (OCDE e USP) ${ }^{\mathrm{b}}$
}

Área ABEIN: 5.9 - Indicadores de Ciência, Tecnologia, Inovação.

Resumo. Este estudo é pioneiro ao apresentar a pesquisa e desenvolvimento (P\&D) pública e privada, direta e indireta, desagregada para 68 setores economia brasileira. Foram utilizados dados de $\mathrm{P} \& \mathrm{D}$ publicados pela primeira vez nas novas contas nacionais do Brasil. A P\&D dos institutos públicos foi identificada e alocada nos setores produtivos de finalidade da pesquisa. Para captar a P\&D indireta incorporada nos insumos intermediários e bens de investimento (nacionais e importados) foram utilizadas matrizes de insumo-produto, de investimentos e o indicador setorial de intensidade em P\&D da OCDE. Os resultados mostram uma grande heterogeneidade setorial na produção e no uso da $\mathrm{P} \& D$. Conclui-se que a $\mathrm{P} \& \mathrm{D}$ indireta é fonte relevante de aquisição de tecnologia tanto para setores dominados pelos fornecedores quanto para baseados em ciência, sobretudo porque o Brasil importa muitos insumos e bens de capital tecnológicos intensivos em P\&D. Ademais, identificou-se que setores de serviços fazem pouca P\&D no Brasil.

Palavras-chave: Pesquisa e Desenvolvimento (P\&D); P\&D incorporada nos produtos; Institutos públicos de pesquisa; Análise de insumo-produto; Setores de atividades econômicas.

Abstract. This study is a pioneer in presenting public and private research and development (R\&D), direct and indirect, disaggregated to 68 Brazilian economy sectors. R\&D data published for the first time in the new Brazilian national accounts were used. R\&D by public institutes was identified and allocated in the productive sectors of R\&D's finality. In order to capture the indirect R\&D incorporated in intermediary inputs and capital goods (national and imported), input-output matrices and investment absorption matrices and an OECD R\&D sectoral intensity indicator were used. The results show a great heterogeneity in the production and use of R\&D. It is concluded that indirect $R \& D$ is a very important source of technological acquisition both for sectors supplier-dominated and for those science-based, especially because Brazil imports many inputs and technological capital goods. In addition, it was identified that services sectors make little R\&D in Brazil.

Keywords: Research and Development (R\&D); Product-embodied R\&D; Public research institutes; Input-output analysis; Sectors of economic activities.

Classificação JEL: O32; L00; C67.

\footnotetext{
a Doutor em Economia pela FEA-USP. E-mail: paulo.morceiro@gmail.com. O presente trabalho foi realizado com apoio da CAPES e da FIPE.

${ }^{\mathrm{b}}$ Economista da OCDE e professor da USP. O conteúdo desta publicação expressa a visão deste autor e não necessariamente representa a visão da OCDE ou dos seus países membros.
} 


\section{Pesquisa \& Desenvolvimento setorial direta e indireta da economia brasileira}

\section{Introdução ${ }^{1}$}

O progresso tecnológico tem sido responsável por grandes transformações que afetam o modo como as pessoas vivem e se relacionam. Ele ocorre principalmente pela introdução de inovações de processo e de produto, que não só modificam as estruturas produtivas e a eficiência dos insumos, como também aumentam as opções da cesta de consumo. Os investimentos em pesquisa e desenvolvimento (P\&D) têm sido o combustível desse progresso tecnológico, especialmente nos países desenvolvidos, que é irradiado pelo comércio para as nações menos inovativas na forma de produtos inovadores, materiais mais eficientes e bens de capital mais produtivos.

O Brasil carece de estudos sobre P\&D que avaliem todos os setores de sua estrutura produtiva (agricultura, indústria e serviços), apesar dos avanços substantivos produzidos pela Pesquisa de Inovação Tecnológica (Pintec), do IBGE, ao diminuir o gap de dados quanto à P\&D privada para diversos setores de atividade. Em geral, as pesquisas brasileiras concentram-se na indústria de transformação (FURTADO; CARVALHO, 2005; DE NEGRI; SALERNO, 2005) e são escassas aquelas que vão além da manufatura. Além disso, o sistema nacional de inovação dos países em desenvolvimento (PEDs) depende muito da P\&D pública (OCDE, 2005, p. 138), a qual não é captada pela Pintec.

Esta pesquisa também não teve conhecimento de algum estudo setorial bem desagregado que mensure a P\&D indireta incorporada nos fluxos de insumos intermediários e nos bens de investimento. A P\&D indireta é uma forma relevante de difusão de tecnologia intersetorial e de aquisição de conhecimentos tecnológicos, especialmente para os setores tradicionais da indústria e dos serviços (CASTELLACCI, 2008; HAUKNES; KNELL, 2009; OCDE, 2005; PAPACONSTANTINOU; SAKURAI; WYCKOFF, 1998). Estes setores aumentam a sua produtividade ao adquirirem inovações incorporadas em insumos intermediários e bens de capital.

O presente artigo objetiva mostrar um retrato da $\mathrm{P} \& D$, pública e privada, direta e indireta, para cerca de 70 setores da estrutura produtiva brasileira, desde a agricultura, indústria até os serviços a partir de dados publicados pela primeira vez nas novas contas nacionais. Trata-se de uma abordagem inédita ao indicar a P\&D realizada por todos os setores da economia brasileira e com elevado grau de detalhamento setorial (mais amplo que o da Pintec), inclusive ao trazer informações da $\mathrm{P} \& \mathrm{D}$ pública, que é muito relevante tanto para os setores tradicionais quanto para os tecnológicos.

Esta pesquisa lidou com um grande volume de dados de várias fontes de informações, em especial das novas contas nacionais do Brasil, além de realizar alguns tratamentos para cumprir com o objetivo proposto. Particularmente, destacam-se as informações dos diversos institutos públicos de pesquisa recebidas no âmbito da Lei de Acesso à Informação. A proposta foi levantar os dispêndios em P\&D feitos pelos órgãos públicos de pesquisa, identificar a finalidade setorial e alocá-los nos respectivos setores de atividade produtiva. Desse modo, foram identificados volumes expressivos de P\&D pública destinados aos setores agropecuário, mineração, outros equipamentos de transportes, saúde pública, entre outros.

Com isso um vetor de P\&D setorial foi criado e através de técnicas de insumo-produto foi possível captar a P\&D indireta incorporada nos insumos intermediários e bens de investimentos nacionais e importados. Para este último ponto foram empregadas informações da matriz de insumo-produto (MIP) e da matriz de absorção de investimentos (MAI) setor por setor.

Verificou-se que o Estado tem um grande papel no desenvolvimento tecnológico brasileiro tanto diretamente, ao fazer $\mathrm{P} \& \mathrm{D}$, quanto indiretamente, por meio de regulamentações setoriais e financiamentos de estímulo à $\mathrm{P} \& \mathrm{D}$. Além disso, foi constatada uma elevada diversidade setorial tanto na produção quanto no uso da $\mathrm{P} \& \mathrm{D}$ e que os insumos intermediários constituem uma forma relevante de aquisição de conhecimento tecnológico, especialmente porque o Brasil depende de modo substantivo de materiais e componentes tecnológicos importados intensivos em P\&D.

Além desta introdução, a seção 2 faz uma revisão bibliográfica sobre P\&D direta e indireta. A seção 3 apresenta as bases de dados utilizadas, o tratamento das informações e a metodologia de insumo-produto

\footnotetext{
${ }^{1}$ Os autores agradecem o suporte técnico dos pesquisadores da divisão das Contas Nacionais e da PINTEC, ambos do IBGE.
} Também agradecemos as sugestões recebidas no Globelics, realizado na Indonésia em 2016, e dos membros do NEREUS-USP. 
empregada. A seção 4 exibe o montante de P\&D realizada por todos os setores produtivos, bem como o esforço tecnológico ( $\mathrm{P} \& \mathrm{D}$ /produção) setorial. A seção 5 mostra a P\&D indireta incorporada nos bens de investimento e nos insumos intermediários adquiridos por setor produtivo. E a seção 6 exibe as conclusões.

\section{O papel da P\&D direta e indireta no progresso tecnológico}

O progresso tecnológico realiza-se por meio de inovações. Schumpeter (1934, cap. 2; 1942, cap. 7) colocou as inovações no centro do desenvolvimento socioeconômico em um processo denominado "destruição criadora" em que tecnologias novas substituem as antigas e geram grandes transformações na sociedade ao longo do tempo. O autor mencionou cinco tipo de inovações: i) introdução de novos produtos (inteiramente novo ou substancialmente aprimorado); ii) introdução de novos métodos de produção; iii) abertura de novos mercados; iv) desenvolvimento de novas fontes de oferta de insumos intermediários; e v) criação de novas estruturas de mercado em uma indústria (SCHUMPETER, 1934, cap. 2).

As inovações ao serem introduzidas no mercado mantêm ou melhoram a competitividade das firmas via aumento de demanda ou redução de custos (OCDE, 2005, cap. 2). Um produto novo pode expandir a participação de mercado da firma inovadora e aumentar a sua margem de lucro, enquanto uma inovação de processo eleva a produtividade e/ou garante uma vantagem de custos sobre seus competidores. Para a sociedade, as inovações geram diversos benefícios como economia de tempo para realizar uma tarefa, a cura de doenças e a mitigação das mudanças climáticas. Pode-se dizer que "[...] os resultados de pesquisas e as novas tecnologias têm frequentemente aspectos de um bem público pois os gastos para torná-las disponíveis a vários usuários são baixos se comparados a seus custos de desenvolvimento.” (OCDE, 2005. p. 30, tradução nossa).

A inovação pode resultar das atividades de $\mathrm{P} \& \mathrm{D}$ realizadas internamente pelas empresas e institutos de pesquisa e, também, da adoção de conhecimentos tecnológicos desenvolvidos por outras instituições. A P\&D objetiva expandir o estoque de conhecimentos científicos e tecnológicos e aplicá-los em mercadorias comercializáveis. Seus laboratórios funcionam como "fábricas de tecnologias" que buscam gerar inovações internamente de modo sistemático e contínuo e absorver tecnologia criadas por outras instituições para aumentar o potencial inovativo (COHEN; LEVINTHAL, 1989). Adicionalmente, há dois modos de se adquirir conhecimento tecnológico externamente. Primeiro, pela difusão desincorporada relacionada à transmissão de ideias, know-how técnico, manuais, patentes, licenças e marcas registradas. Segundo, pela difusão incorporada nos produtos que ocorre quando a inovação inicial está incorporada neles (bens ou serviços). "Uma vez que outras indústrias usam este produto como um insumo intermediário ou um bem de capital, a inovação torna-se incorporada em muitos outros produtos, incluindo aqueles usados para fins de demanda final (por exemplo, consumo, investimento e exportações)" (DIETZENBACHER; LOS, 2002, p. 408). Dessa maneira, além da $P \& D$, a inovação pode resultar de novas combinações e da aplicação de tecnologias incorporadas nos insumos intermediários e, também, da adoção de novas tecnologias materializadas nos bens de capital (máquinas e equipamentos) (OCDE, 2005, p. 34-36).

$\mathrm{Na}$ busca pela inovação, algumas atividades inovativas são relativamente mais importantes para algumas indústrias que para outras. A P\&D é vital para os setores manufatureiros de alta e média-alta tecnologia e para os serviços intensivos em conhecimento como softwares e outros serviços de informação (GALINDO-RUEDA; VERGER, 2016; OCDE, 2005, p. 37). No entanto, para diversos setores de baixa e média-baixa tecnologia e para os serviços tradicionais a atividade de P\&D interna é menos relevante que a adoção de tecnologias desenvolvidas externamente, principalmente na forma de bens de capital e insumos intermediários (CASTELLACCI, 2008; HAUKNES; KNELL, 2009; OCDE, 2005; PAVITT, 1984). Geralmente, as atividades inovativas nos setores tradicionais envolvem a incorporação de bens de capital e componentes de alta tecnologia, como tecnologias de informação e biotecnologia, aplicados à indústria de processamento de alimentos (OCDE, 2005, p. 37). Vale mencionar que aquisição de novas tecnologias incorporadas nas máquinas e nos equipamentos é o tipo de inovação mais relevante para os países em desenvolvimento (OCDE, 2005, p. 138), inclusive para o Brasil (PINTEC, 2016).

Muitos estudos têm mostrado que há elevada heterogeneidade setorial tanto na produção de tecnologia (GALINDO-RUEDA; VERGER, 2016; HATZICHRONOGLOU, 1997) quanto no uso de

\footnotetext{
${ }^{2}$ Sobre conhecimento incorporado e desincorporado, ver Sabato (1979) e Papaconstantinou, Sakurai e Wyckoff (1998).
} 
tecnologias incorporadas nos produtos (CASTELLACCI, 2008; PAPACONSTANTINOU; SAKURAI; WYCKOFF, 1998; PAVITT, 1984). Alguns trabalhos, comentados na sequência e que servem de base para este trabalho, utilizaram matrizes de insumo-produto e de fluxos de investimento para rastrear a tecnologia incorporada no produto ao "[...] assumir que o progresso tecnológico é proporcional aos investimentos em P\&D e que a P\&D incorporada em um produto é a mesma para cada um dos seus compradores." (DIETZENBACHER; LOS, 2002, p. 408).

Papaconstantinou, Sakurai e Wyckoff (1998) utilizaram dados de 1990 para dez países da OCDE e mostraram que as inovações são desenvolvidas principalmente por poucos setores manufatureiros intensivos em P\&D e os principais usuários de tecnologias são os setores de serviços, especialmente ao adquirir bens de capital sofisticados tecnologicamente. Além disso, os autores verificaram que os setores manufatureiros, sobretudo de alta e média-alta tecnologia dependem relativamente menos da tecnologia embarcada nas máquinas e equipamentos, pois os insumos intermediários são a principal forma de aquisição de tecnologia externa. Países grandes economicamente, como Estados Unidos, Japão e Alemanha, buscam menos tecnologia no exterior que países pequenos, os quais dependem da importação para mais de $50 \%$ da tecnologia adquirida (PAPACONSTANTINOU; SAKURAI; WYCKOFF, 1998).

Hauknes e Knell (2009) utilizaram dados de 2000 para cinco países desenvolvidos (Estados Unidos, Alemanha, França, Suécia e Noruega) e mensuraram que a P\&D incorporada nos produtos representou quase metade da P\&D total utilizada pela economia; além disso, eles encontraram uma variação substancial entre os setores produtivos. Os autores adotaram uma agregação de oito grandes grupos de setores baseada na taxonomia de Pavitt (1984), modificada para incluir os setores de serviços. Hauknes e Knell (2009) verificaram que nos grupos dos setores tradicionais (como agropecuária e manufatura de baixa e médiabaixa tecnologia) e dos serviços (exceto serviços intensivos em conhecimento) mais da metade da P\&D total vem de fora - assim como nos setores dominados pelos fornecedores de Pavitt (1984) -, enquanto aqueles baseados em ciência (como a manufatura de alta tecnologia) e serviços intensivos em conhecimento (como softwares) mais da metade da P\&D total é realizada internamente. Assim, os dois primeiros grupos são usuários e os dois últimos produtores de tecnologia, similar ao padrão de produção e uso de inovações descrito por Pavitt (1984).

Diferente dos estudos anteriores, a presente pesquisa adota dados mais desagregados setorialmente e atualizados para o Brasil, além de incluir informações do setor público que nos PEDs representam cerca de metade dos investimentos em P\&D. Ademais, conforme descrito na seção metodológica, utiliza-se uma matriz de investimento setor por setor de maior qualidade que a empregada nos estudos precedentes.

\section{Dados e metodologia}

\subsection{Fonte das informações}

Este trabalho baseia-se em várias fontes de informações nacionais e internacionais, que serão comentadas na sequência. A maioria dos dados são para o ano de 2013 e seguiu-se aqui a desagregação em 68 setores de atividade do novo Sistema de Contas Nacionais - Referência 2010 (SCN Ref. 2010) produzido pelo IBGE. As informações setoriais de $\mathrm{P} \& \mathrm{D}$, valor da produção, valor adicionado bruto (PIB a preços básicos) e empregos foram obtidas a partir das Contas Nacionais (IBGE, 2015a).

Adotaram-se as matrizes de insumo-produto (MIP) estimadas pelo método desenvolvido por Guilhoto e Sesso Filho $(2005,2010)$ para calcular a P\&D indireta da cadeia produtiva setorial. Essas MIP's estão disponíveis no site do Núcleo de Economia Regional e Urbana (Nereus) da Universidade de São Paulo e têm a vantagem de serem mais atualizadas que as publicadas pelo IBGE.

Para calcular a P\&D indireta incorporada nos bens de investimento adquiridos pelos setores produtivos utilizaram-se as matrizes de investimento estimadas por Miguez (2016). ${ }^{3}$ Este autor estimou matrizes de absorção de investimento (MAI), dos bens e serviços de investimento nacionais e importados, na agregação de 27 produtos por 49 setores desde 2000 até 2013. Os produtos foram alocados nos respectivos setores vinculados de modo que este estudo trabalhou com a MAI setor por setor. Esta pesquisa adotou a média das MAI de 2010 a 2013 (a preços de 2013) ao invés da MAI de 2013, pelo fato de os investimentos serem mais sazonais que o consumo intermediário, em decorrência dos seus diferentes ciclos

\footnotetext{
${ }^{3}$ Vale ressaltar que o Brasil não possui matrizes oficiais de investimento setor por setor.
} 
de negócios e período de maturação. Como a MAI é mais agregada que os 68 setores deste estudo, foi necessário desagregar alguns setores, principalmente de serviços, conforme procedimentos metodológicos desenvolvidos para esta finalidade. ${ }^{4}$

\subsection{Pesquisa e Desenvolvimento (P\&D) no Sistema de Contas Nacionais Ref. 2010}

A quarta e última edição do manual internacional das contas nacionais passou a considerar como investimento os dispêndios setoriais em P\&D (SNA 2008, 2009). Além da maior difusão das estatísticas de $\mathrm{P} \& \mathrm{D}$, com a adoção do novo marco estrutural das contas nacionais, será possível obter dados setoriais anualmente ao invés de a cada três anos, como é feito pela publicação da Pintec. Com isso, desde 2015, o IBGE passou a divulgar informações de investimentos em P\&D para os 68 setores de atividades do novo SCN Ref. 2010, com dados anuais desde 2010.

A definição de $\mathrm{P} \& \mathrm{D}$ nas novas contas nacionais é praticamente igual à do manual de Frascati e há bastante sobreposição na forma de mensuração. Dessa maneira, os valores de P\&D nas duas fontes são semelhantes (KER; GALINDO-RUEDA, 2017). No entanto, o SCN Ref. 2010 não inclui nos investimentos em P\&D despesas como transferências, subsídios e despesas de capital fixo. As duas primeiras, apesar de adotadas pelo MCTI, podem resultar em dupla contagem e a última pode gerar valores diferentes quando comparada à Pintec do IBGE.

No SCN Ref. 2010, a mensuração do valor investido em P\&D é obtida pela abordagem da soma dos custos totais envolvidos nessa atividade quando ela não é objeto de transação no mercado - haja vista que a maior parte da $\mathrm{P} \& \mathrm{D}$ não é comercial e sim de uso interno -, a partir da soma das remunerações, do consumo intermediário e do consumo de capital fixo (IBGE, 2015, p. 3). A soma desses três componentes resulta na produção do "produto P\&D” por todos os 68 setores de atividade.

Vale ressaltar que o SCN Ref. 2010 divulga informações de P\&D para um conjunto maior de setores que a Pintec, inclusive para o setor público ${ }^{5}$ que investiu cerca de metade da P\&D total do Brasil no período recente. Outra vantagem dos dados de P\&D do SCN Ref. 2010 para este estudo é que eles já estão padronizados na mesma classificação setorial da MIP e são mensurados a preços básicos.

\subsection{Tratamento dos dados da $P \& D$ dos institutos públicos de pesquisa e da Petrobras}

Um diferencial do presente estudo é o tratamento e inclusão das informações de P\&D realizada pelos institutos públicos de pesquisa (IPP) com finalidade setorial bem definida. A P\&D dessas instituições está alocada no setor "administração pública, defesa e seguridade social" (doravante, administração pública) nas contas nacionais, o qual foi responsável por 19,1\% dos investimentos do Brasil em P\&D, em 2013. Após dezenas de pedidos pela Lei de Acesso à Informação foi possível identificar o valor investido pelos principais institutos públicos de pesquisa do Brasil. Assim que se determinou a finalidade setorial da P\&D por eles realizada, a mesma foi retirada do setor ao qual pertencia (administração pública) e alocada no de "finalidade da pesquisa". E quando não foi possível identificar a finalidade da P\&D porque a instituição faz pesquisa para múltiplos setores ou possui uma finalidade transversal - como o Instituto de Pesquisas Tecnológicas do Estado de São Paulo (IPT) e o Instituto Nacional de Pesquisas Espaciais (Inpe) - ela foi mantida no setor da administração pública. Este estudo identificou a finalidades setorial de $60 \%$ da P\&D da administração pública, sendo os principais: i) agropecuária (por ex., Empresa Brasileira de Pesquisa Agropecuária - Embrapa e o Instituto Agronômico de Campinas - IAC); ii) setor de mineração (por ex., Companhia de Pesquisa de Recursos Minerais - CPRM e Centro de Tecnologia Mineral); iii) setor de informática e eletrônicos (por ex., Centro de Excelência em Tecnologia Eletrônica Avançada e o Centro de Tecnologia da Informação Renato Archer); iv) setor de outros equipamentos de transportes (por ex., o Departamento de Ciência e Tecnologia Aeroespacial e a Agência Espacial Brasileira); v) setor de saúde pública (por ex., Fiocruz e Instituto Butantan); vi) setor de alimentos (por ex., Instituto de Tecnologia de Alimentos); entre outros. O Apêndice A exibe o valor da P\&D realizada por cada IPP e os setores produtivos da finalidade da P\&D.

\footnotetext{
${ }^{4}$ Este artigo faz parte de um estudo maior em que consta as técnicas utilizadas para a referida desagregação, além de outros procedimentos metodológicos mais detalhados.

${ }^{5}$ Os setores públicos são: administração pública, defesa e seguridade social; educação pública; e saúde pública.
} 
Alguns institutos de pesquisa possuem seus recursos alocados nos "serviços de arquitetura, engenharia, testes/análises técnicas e P\&D” no SCN Ref. 2010 pelo fato desse setor reunir os laboratórios de P\&D com CNPJ próprio. Um exemplo é o Centro de Pesquisas Leopoldo Américo Miguez de Mello (Cenpes), laboratório de P\&D da Petrobras, empresa que mais investe em P\&D no Brasil. A sua pesquisa concentra-se na área de exploração e produção de petróleo, mas também há pesquisas nas áreas de refino de petróleo, bicombustíveis e no setor de energia. Da mesma forma, a P\&D realizada pela Petrobras também foi redistribuída para o setor de finalidade da pesquisa, conforme o Apêndice A.

\subsection{Metodologia}

\subsubsection{P\&D a partir das novas contas nacionais referência 2010}

A P\&D direta para cada um dos 68 setores de atividade foi calculada como segue: $P \& D_{j}$ direta $=P \& D$ interna $_{j}+P \& D$ externa $_{j}$

Onde a $P \& D$ interna $_{j}$ é a produção do produto $\mathrm{P} \& \mathrm{D}$ em $\mathrm{R} \$$ a preços básicos do setor $\mathrm{j}$, variável que consta na Matriz de Produção do SCN Ref. 2010. A P\&D externa ${ }_{j}$ corresponde ao consumo intermediário do produto $P \& D$ em Reais a preços básicos do setor j, variável que consta na Matriz de Usos. ${ }^{6}$

Para cada um dos 68 setores de atividade, a P\&D direta é a soma da produção de P\&D própria (P\&D interna) e o consumo intermediário de P\&D (P\&D externa), exceto para o setor "7180 - Serviços de arquitetura, engenharia, testes/análises técnicas e P\&D”. Para evitar dupla contagem, toda a P\&D externa foi subtraída do setor "7180 - Serviços de arquitetura, engenharia, testes/análises técnicas e P\&D", que é o setor responsável por comercializar a P\&D para os demais setores da economia.

Considere $r_{j}$ e $r_{i}$ a intensidade em P\&D direta do setor doméstico $j$ e $i$, respectivamente:

$r_{j}=\frac{P \& D_{j}}{X_{j}} \quad$ e $\quad r_{i}=\frac{P \& D_{i}}{X_{i}}$

Em que $X_{j}$ e $X_{i}$ são o valor da produção do setor $j$ e do setor $i$ a preços básicos.

\subsubsection{P\&D incorporada nos insumos intermediários e nos bens e serviços de investimento nacionais e estrangeiros}

Considere como $P \& D$ indireta toda a $\mathrm{P} \& \mathrm{D}$ incorporada nos insumos intermediários (cadeia produtiva) e nos bens de investimento comprados pelo setor $j$ a partir do setor $i$. Neste estudo, vamos adotar praticamente os mesmos procedimentos metodológicos de Hauknes e Knell (2009, p. 460) que serão descritos na sequência. ${ }^{7}$ Os autores da nota anterior adotaram a suposição da proporcionalidade em que toda venda do setor $i$ para o setor $j$ incorpora $\mathrm{P} \& \mathrm{D}$ proporcional ao montante de bens e serviços comprados do setor i. Assim, nós assumimos que se o setor $i$ investiu R $\$ 50$ em P\&D e vendeu R $\$ 1.000$ de produção total, sendo R $\$ 700$ para o setor $j$ e $\mathrm{R} \$ 300$ para o setor k, pela suposição da proporcionalidade, o setor $j$ adquiriu indiretamente $\mathrm{R} \$ 35$ de $\mathrm{P} \& \mathrm{D}$ do setor $i$ e o setor $k$ adquiriu $\mathrm{R} \$ 15 .^{8}$ Então, cada $\mathrm{R} \$ 1,00$ de produção do setor i possui $\mathrm{R} \$ 0,05$ de $\mathrm{P} \& \mathrm{D}$ incorporada.

O modelo de Leontief separa a tecnologia de produção (matriz de coeficientes técnicos) da demanda final. No modelo, $\mathrm{N}$ setores são representados por um vetor de produção $x$ e o vetor da demanda final $y$ : $x=\boldsymbol{A} x+y$

Em que $\boldsymbol{A}$ representa a matriz de coeficientes técnicos dos insumos domésticos interindustriais e $\boldsymbol{A} x$ corresponde aos insumos intermediários domésticos necessários para a produção. Dado que inversa da matriz $(1-\mathbf{A})$ exista, podemos obter:

$x=(1-\boldsymbol{A})^{-1} y \equiv \boldsymbol{B} y$

Onde $\boldsymbol{B}$ é a matriz inversa de Leontief de $\boldsymbol{A}$. Os elementos $b_{i j}$ da matriz $\boldsymbol{B}$ são os insumos domésticos diretos e indiretos requeridos pelo aumento na produção do setor $i$ necessário para produzir uma unidade adicional de bens do setor $j$ destinada a demanda final $(i, j=1, \ldots ., \mathrm{N}$, com $\mathrm{N}$ setores $)$.

\footnotetext{
${ }^{6}$ A P\&D externa foi ajustada de preços do consumidor para preços básicos.

7 Terleckyj (1974) é referência seminal da metodologia adotada neste estudo. Essa metodologia foi utilizada por Scherer (1982), Papaconstantinou, Sakurai e Wyckoff (1998), entre outros. Utilizaremos a versão adotada Hauknes e Knell (2009) por incorporar os avanços metodológicos precedentes.

${ }^{8}$ Respectivamente, $(\mathrm{R} \$ 700 / \mathrm{R} \$ 1000 \times \mathrm{R} \$ 50)$ para o setor $i$ e $(\mathrm{R} \$ 300 / \mathrm{R} \$ 1000 \times \mathrm{R} \$ 50)$ para o setor $k$.
} 
A intensidade em $P \& D$ total do setor $j, s_{j}^{x}$, inclui os investimentos em P\&D do próprio setor, a P\&D incorporada nos insumos intermediários domésticos e estrangeiros e a P\&D incorporada nos bens e serviços de investimento comprados pelo setor $j$ no mercado doméstico e no exterior.

Dado a intensidade em P\&D direta do setor $i, r_{i}$, a matriz $\boldsymbol{T}$ corresponde a P\&D doméstica direta e indireta da cadeia produtiva por unidade da demanda final do setor $j$ que é obtida ao multiplicar a intensidade em P\&D pelos elementos $b_{i j}$ :

$\boldsymbol{T}=\hat{r} \boldsymbol{B}$

Onde o $\left(^{\wedge}\right)$ denota a matriz diagonalizada dos elementos do vetor correspondente $r$. A matriz $\boldsymbol{T}$ contém dupla-contagem quando o foco é a intensidade em P\&D direta e indireta da cadeia produtiva em relação a produção (que é o nosso caso) ao invés da demanda final. Papaconstantinou, Sakurai e Wyckoff (1998), seguindo Miller e Blair (2009), contornaram essa dupla contagem ao tratar o setor j como um setor exógeno na MIP modificada $\boldsymbol{T}_{x}$ :

$\boldsymbol{T}_{x}=\hat{r} \boldsymbol{B}^{*}$

que mensura a P\&D direta e indireta da cadeia produtiva doméstica relativa a produção total desse setor. A expressão (V) mensura a intensidade tecnológica por unidade da demanda final do setor $j$ e (VI) mensura a intensidade tecnológica por unidade da produção. Assim, ao retirar os elementos da diagonal em (VI), que representa a $\mathrm{P} \& \mathrm{D}$ do próprio setor, temos a intensidade em $\mathrm{P} \& \mathrm{D}$ incorporada nos insumos intermediários domésticos adquiridos pelo setor $j\left(t_{j}^{d}\right)$ :

$t_{j}^{d}=\sum_{i=1, i \neq j}^{N}\left(r_{i}^{d} \frac{b_{i j}}{b_{j j}}\right)$

A intensidade em P\&D direta e indireta da cadeia produtiva doméstica $s_{j}^{d}$ - isto é, a P\&D direta $r^{d}$ e a P\&D incorporada nos insumos intermediários adquiridos no mercado doméstico $t^{d}-$ do setor $j$ calculada por:

$s_{j}^{d}=r_{j}^{d}+t_{j}^{d}=\sum_{i=1}^{N}\left(r_{i}^{d} \frac{b_{i j}}{b_{j j}}\right)$

Considere $t_{j}^{m}$ a P\&D indireta da cadeia produtiva dos insumos importados pelo setor $j$ :

$t_{j}^{m}=\sum_{i=1}^{N}\left(r_{i}^{f} m_{i j}\right)$

Em que $m_{i j}$ são os elementos da matriz $\mathbf{M}$ de coeficientes técnicos dos insumos importados de todos os setores estrangeiros $i$ pelo setor nacional $j$, em termos de unidade de produção do setor doméstico $j$. Considere $r_{i}^{f}$ a fronteira tecnológica do setor $i$ definida como a intensidade em P\&D da OCDE direta e indireta (indireta apenas da cadeia produtiva). Foi usada a intensidade em P\&D setorial da OCDE calculada por Galindo-Rueda e Verger (2016), e adotou-se a matriz de insumo-produto dos Estados Unidos para captar a P\&D indireta.

Quanto aos bens de investimento, considere $\mathbf{C}$ a matriz de investimento por unidade de produção do setor $j$ - isto é, a MAI por unidade de produção do setor $j$, que é o setor que realizou os investimentos , em que os elementos $c_{i j}^{d}$ da matriz $\mathbf{C}$ são os bens e serviços produzidos domesticamente pelo setor $i$ adquiridos pelo setor $j$ para fins de investimento dividido pela produção do setor $j$ e os elementos $c_{i j}^{m}$ da matriz $\mathbf{C}$ são os bens e serviços produzidos no exterior pelo setor $i$ adquiridos pelo setor doméstico $j$ para fins de investimento dividido pela produção doméstica do setor $j$. Dessa forma, a P\&D indireta incorporada nos bens e serviços de investimento nacionais produzidos pelo setor $i$ adquiridos pelo setor $j$ é dada por $\left(t_{j}^{d c}\right)$ :

$t_{j}^{d c}=\sum_{i=1}^{N}\left(s_{i}^{d} c_{i j}^{d}\right)$

Em que $s_{i}^{d}$ é a P\&D direta e indireta da cadeia produtiva doméstica do setor $i$. Por fim, $t_{j}^{m c}$ representa a $\mathrm{P} \& \mathrm{D}$ indireta incorporada nos bens e serviços de investimento estrangeiros produzidos pelo setor $i$ adquiridos pelo setor doméstico $j$ :

$t_{j}^{m c}=\sum_{i=1}^{N}\left(r_{i}^{f} c_{i j}^{m}\right)$

Vale ressaltar que a forma de calcular a P\&D indireta incorporada nos bens de investimento é diferente da empregada por Hauknes e Knell (2009). Em geral, os países só divulgam um vetor de investimento, dessa forma, não é possível identificar os setores que fazem os investimentos. Hauknes e 
Knell (2009) adotaram uma solução de second best ao distribuir o vetor de investimento de acordo com a estrutura da matriz de Leontief. Dessa forma, esta pesquisa utiliza dados de investimento com maior precisão que os estudos anteriores ao identificar tanto os setores produtores quanto os usuários dos bens e serviços de investimento.

Em resumo, a partir de (II), (VII), (IX), (X) e (XI) temos $s_{j}^{x}$ que corresponde a intensidade em P\&D total do setor $j$ :

$s_{j}^{x}=r_{j}^{d}+t_{j}^{d}+t_{j}^{m}+t_{j}^{d c}+t_{j}^{d m}$

A partir da intensidade em P\&D total podemos mensurar o multiplicador tecnológico (ou multiplicador de P\&D), $m t_{j}$, do setor $j$ como:

$m t_{j}=s_{j}^{x} / r_{j}^{d}$

A seguir, a seção 4 aborda a P\&D direta e a seção 5 a P\&D indireta e o multiplicador tecnológico.

\section{Pesquisa e Desenvolvimento realizada pelos setores de atividade}

Em 2013, os investimentos em P\&D realizados pela economia brasileira foram de R $\$ 63,5$ bilhões em valores de 2017, que corresponderam a 1,08\% do PIB do Brasil. Esse montante está distribuído na Figura 1 pelos setores de atividade em que a P\&D foi realizada. Ressalta-se que essa distribuição já considera a alocação da $\mathrm{P} \& \mathrm{D}$ dos institutos públicos de pesquisa com finalidade setorial definida nos respectivos setores de atividade, conforme a alocação exibida no Apêndice A.

No Brasil, a maior parte dos investimentos em P\&D foi realizada pelos serviços públicos, responsáveis por $42,5 \%$ dos investimentos; o setor de educação pública investiu $31,5 \%$; administração pública, 7,7\%; e saúde pública, 3,4\% (Figura 1).

$\mathrm{Na}$ educação pública, consideram-se como investimentos em P\&D os salários e demais remunerações dos professores atuantes nos programas de pós-graduação strictu senso reconhecidos pela Capes e as despesas de custeio das universidades, inclusive bolsas de pesquisa dos alunos (MCTI, 2009). Embora as atividades dos professores de pós-graduação incluam ensino, pesquisas com ou sem finalidade comercial e atividades de treinamento, todas elas são consideradas $\mathrm{P} \& \mathrm{D}$, mesmo que prevaleçam as atividades de ensino. Vale dizer que a forma de contabilizar a $P \& D$ do setor de educação é uma prática mundial pautada no Manual Frascati (OECD, 2015) e o Brasil a segue.

A administração pública reúne vários institutos públicos de pesquisa com finalidade diversa (transversal ou multisetorial) como o IPT, o Inpe, o Instituto Nacional de Pesquisas da Amazônia (Inpa) e o Instituto de Tecnologia do Paraná (Tecpar). Dada a dificuldade na identificação da finalidade setorial da pesquisa feita, a P\&D desses institutos e de alguns outros foi mantida no setor da administração pública. Já naqueles em que há clara destinação setorial, como a Embrapa, seus dispêndios foram alocados nos setores respectivos (neste caso, nos setores da agropecuário conforme Apêndice A).

No setor de saúde pública sobressai a P\&D realizada pela Fundação Oswaldo Cruz (Fiocruz), que desembolsou aproximadamente R \$ 1,4 bilhão (valores de 2017) em pesquisas. Os Institutos Butantan, Vital Brazil, Adolfo Lutz e Pasteur são outras importantes instituições que fazem P\&D na área da saúde pública. Essas entidades produzem conhecimentos - principalmente nos temas relacionados à saúde coletiva de um país tropical não desenvolvido - em doenças como Aids, Chagas, tuberculose, esquistossomose, malária, hanseníase, sarampo, rubéola, meningites, hepatites e vacinas, soros e patógenos de grande interesse social.

Depois dos serviços públicos, a indústria de transformação é o agrupamento setorial que mais faz pesquisa, com 32,4\% da P\&D total do país (Figura 1). Dentro da indústria de transformação há um grupo de setores de maior intensidade tecnológica que realiza quase $80 \%$ da $\mathrm{P} \& \mathrm{D}$ manufatureira, apesar de representar apenas 1/3 do PIB manufatureiro. ${ }^{9}$ Apenas cinco setores do grupo de maior intensidade tecnológica realizaram mais de $50 \%$ da P\&D manufatureira, a saber: automóveis, caminhões e ônibus, exceto peças (com 5,40\% da P\&D total do Brasil); equipamentos de informática, eletrônicos e ópticos

\footnotetext{
${ }^{9} \mathrm{O}$ grupo manufatureiro de maior intensidade tecnológica é composto pelos setores de alta e média-alta intensidade em $\mathrm{P} \& \mathrm{D}$ da nova classificação da OCDE, enquanto que o grupo manufatureiro de menor intensidade tecnológica é composto pelos setores de média e média-baixa intensidade em P\&D da mesma classificação. A classificação da OCDE foi apresentada por GalindoRueda e Verger (2016).
} 
(3,67\%); químicos orgânicos, inorgânicos, resinas e elastômeros (2,98\%); outros equipamentos de transporte $(2,60 \%)$; e farmoquímicos e farmacêuticos (2,37\%) (Figura 1$)$.

Figura 1 - Investimento brasileiro em Pesquisa e Desenvolvimento, em 2013

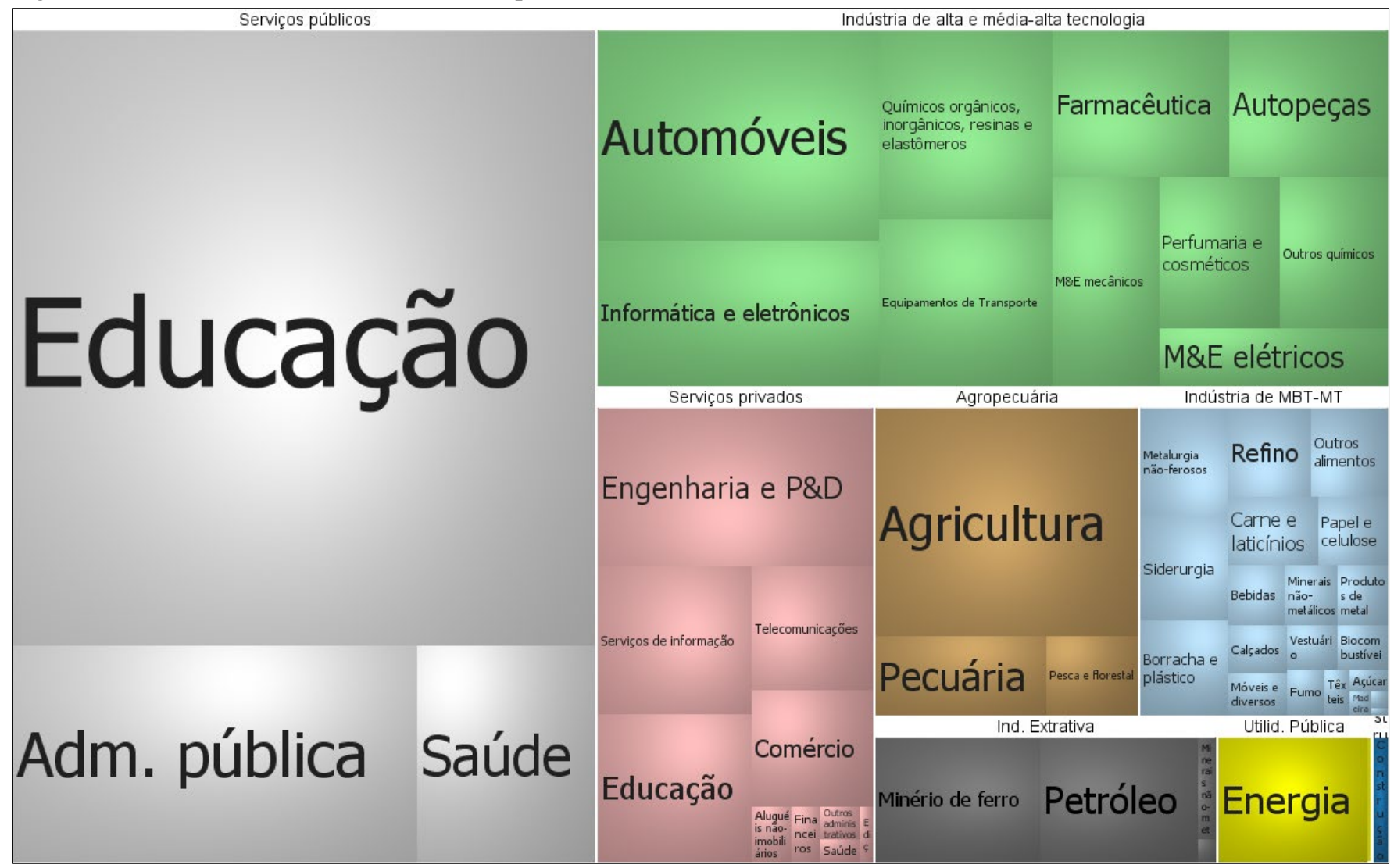

Fonte: IBGE (2015a) e dados obtidos pela Lei de Acesso à Informação. Cálculos e elaboração do autor.

Todos os dez setores do grupo de maior intensidade tecnológica investiram em P\&D mais que qualquer um daqueles 20 pertencentes ao grupo manufatureiro de menor intensidade tecnológica (Figura 1), evidenciando que os recursos para P\&D são investidos de modo desigual e concentrado setorialmente. Essa não é uma característica só do Brasil, é um padrão verificado em outros países. Em geral, poucos setores fazem a maior parte da P\&D e são os maiores responsáveis pela mudança tecnológica (DOSI; PAVITT; SOETE, 1990, p. 90; JARUZELSKI; STAACK; CHWALIK, 2017; PAPACONSTANTINOU; SAKURAI; WYCKOFF, 1998). O principal motivo deve-se principalmente ao fato de as oportunidades tecnológicas e o potencial inovativo serem muito mais elevados nesses setores que nos demais, conforme apontado por Breschi e Malerba (1997) e Castellacci (2008).

O terceiro agrupamento que mais realizou P\&D foram os serviços privados, com $11,2 \%$ da $P \& D$ total do Brasil (Figura 1). Apesar de formarem mais de 50\% do PIB brasileiro, apenas um número limitado de setores desse grupamento faz P\&D de modo contínuo. Somente quatro setores investiram mais de $80 \%$ de toda a P\&D dos serviços privados, a saber: arquitetura, engenharia, análises técnicas e P\&D (com 3,93\% da P\&D total do Brasil); desenvolvimento de sistemas e outros serviços de informação (2,06\%); educação privada (2,05\%); e telecomunicações (1,35\%). O primeiro setor mencionado inclui a divisão 72 da CNAE 2.0 denominada "Pesquisa e Desenvolvimento Científico", a qual inclui os laboratórios das empresas que possuem centros de P\&D independentes de sua atividade principal ${ }^{12}$ e os institutos privados de pesquisa ${ }^{13}$. Dessa maneira, a divisão 72 inclui laboratórios de P\&D dos mais variados setores de atividade, de serviços

\footnotetext{
12 Exceto o Cenpes que foi alocado nos setores de atuação da Petrobras, conforme informado na metodologia deste estudo.

${ }^{13}$ A divisão 72 é bastante pulverizada com mais de mil empresas que fazem pesquisas classificadas nesse setor. Alguns exemplos: Centro de Tecnologia Canavieira (CTC), Natura Inovação e Tecnologia de Produtos; Quintiles Brasil, Cencoderma Instituição de Pesquisa e Desenvolvimento de Cosméticos, Parexcel Internacional Pesquisas Clínicas, RPS do Brasil Serviços de Pesquisa e Icon Pesquisas Clínicas.
} 
ou não. Certamente, a pesquisa realizada pelo laboratório de $\mathrm{P} \& \mathrm{D}$ tem finalidade relacionada ao setor de atuação da empresa, mas o IBGE não faz esse tratamento dos dados, por isso, deve-se ter cuidado ao interpretar as informações desse primeiro setor. O segundo setor, desenvolvimento de sistemas e outros serviços de informação, inclui a fabricação de softwares, que é o principal segmento dos serviços privados em montante de P\&D investido (JARUZELSKI; STAACK; SHINOZAKI, 2016) ou em intensidade em P\&D (GALINDO-RUEDA; VERGER, 2016). Embora seja dominado por gigantes, como Alphabet, Microsoft, Oracle e SAP, o Brasil possui uma empresa entre os 100 maiores gastos empresariais em P\&D do setor de softwares: a TOTVS S.A. ${ }^{14}$

No restante, a maioria dos setores de serviços privados, como comércio e reparação de veículos e motocicletas, restaurantes, hotéis, serviços jurídicos, serviços domésticos, serviços pessoais, segurança privada, entre outros, não fazem $P \& D$ de modo sistemático ou não foram localizados investimentos em P\&D nas fontes consultadas pelo IBGE. É uma característica estrutural de grande parte dos setores de serviços registrar pouco investimento em P\&D (EVANGELISTA, 2000; GALINDO-RUEDA; VERGER, 2016; HIPP; GRUPP, 2005), uma vez que eles dependem menos dos laboratórios de pesquisa comparativamente à manufatura para manterem-se competitivos. Em geral, na maioria dos serviços outras atividades são mais importantes que a $\mathrm{P} \& \mathrm{D}$, como a implementação de novas técnicas de gestão, novas estratégias de marketing, treinamento, mudanças na organização do trabalho e aquisição de máquinas e softwares. Também cabe registrar que há um predomínio de firmas pequenas e muita atividade informal em segmentos relevantes - por exemplo, comércio, transportes, contabilidade e serviços pessoais -, especialmente nos países em desenvolvimento. Por isso, a atividade de P\&D é ainda escassa.

A agropecuária é o quarto agrupamento que mais fez P\&D no Brasil, com 7,4\% dos dispêndios totais (Figura 1). Os agricultores não realizam pesquisa sobre a semente que utilizarão, eles optam por adquiri-la de empresas privadas especializadas (como a Monsanto ou Syngenta) e de IPP. Isso ocorre pela impossibilidade de restringir o acesso a semente por parte dos concorrentes, dado que outro agricultor pode facilmente coletar uma muda e replantá-la, sem contribuir com os custos de seu desenvolvimento. Dessa forma, a agropecuária brasileira beneficia-se da P\&D realizada pelos IPP, principalmente Embrapa e institutos estaduais de pesquisa (Ver Apêndice A). A Embrapa é a principal instituição que faz P\&D no Brasil, com investimentos da ordem de R \$ 3,3 bilhões de 2017 e conta com um grupo de pesquisadores permanentes (em 2013, totalizavam 2.437, dos quais 85\% são doutores e pós-doutores). O foco da pesquisa dos institutos públicos concentra-se maciçamente na área agrícola, mas parcela razoável é empregada na pecuária, produção florestal, pesca e aquicultura, conforme exibido na Figura 1. Na área agrícola, o esforço de pesquisa mantém o país altamente competitivo internacionalmente, por exemplo, ao ampliar a área plantada para regiões que já foram consideradas inapropriadas para produção agrícola (como o cerrado), adaptar sementes a climas hostis e aumentar da produtividade por hectare plantado.

A indústria extrativa é o quinto agrupamento, com 4,3\% dos investimentos em P\&D do país. Duas áreas se destacam. Primeiro, a P\&D realizada pelo setor de exploração de petróleo e gás natural, para viabilizar as operações a grandes profundidades no litoral brasileiro feita pela Petrobras. É importante ressaltar que há uma regulação da Agência Nacional de Petróleo, Gás Natural e Biocombustíveis (ANP) que determina que empresas de extração e produção de petróleo e gás natural invistam $1,0 \%$ da receita bruta em atividades de P\&D. Segundo, a P\&D realizada pela empresa Vale e pelos institutos públicos, especialmente a CPRM e o Centro de Tecnologia Mineral (Cetem). Desse modo, direta e indiretamente, o Estado estimula a pesquisa na indústria extrativa.

Finalmente, o setor de energia elétrica realizou 1,9\% da P\&D do país. Nesse setor, o Estado também tem um papel ativo por meio de pesquisas conduzidas pela Comissão Nacional de Energia Nuclear (Cnem) e via regulação do Programa de Pesquisa e Desenvolvimento Tecnológico do Setor de Energia Elétrica, da Agência Nacional de Energia Elétrica (Aneel), que determina que empresas de geração e distribuição de energia destinem $1,0 \%$ da receita operacional líquida para este programa, sendo $0,2 \%$ a $0,4 \%$ do total destinados inteiramente às atividades de $\mathrm{P} \& \mathrm{D}$.

\footnotetext{
${ }^{14}$ Em 2013, a TOTVS S.A. investiu aproximadamente 12,3\% das receitas totais em P\&D, percentual que representou cerca de R\$ 115 milhões, conforme a base de dados de Jaruzelski, Staack e Chwalik (2017).
} 
Outra forma de verificar o esforço tecnológico setorial é pela intensidade em $\mathrm{P} \& \mathrm{D}$ (P\&D/produção), conforme apontaram Hatzichronoglou (1997) e OECD (2003, p. 157). Maiores intensidades em P\&D criam maiores oportunidades tecnológicas e ampliam a probabilidade de se descobrir e desenvolver produtos novos. A demanda de produtos inovadores e intensivos em $\mathrm{P} \& \mathrm{D}$ crescem mais rápido, inclusive no comércio internacional (LALL, 2000), e ampliam a parcela de mercado das firmas inovadoras. O Gráfico 1 exibe os 30 setores da economia brasileira com os maiores esforços em $\mathrm{P} \& D$ relativos à produção setorial, excluídos os serviços públicos. Nota-se que, entre os líderes setoriais, a manufatura predomina em número de setores e maiores esforços em P\&D. Dos 30 setores, 18 são da manufatura, e quatro estão posicionados entre os cinco primeiros.

Gráfico 1 - Esforço tecnológico: P\&D dividido pela produção setorial, em 2013, em \%

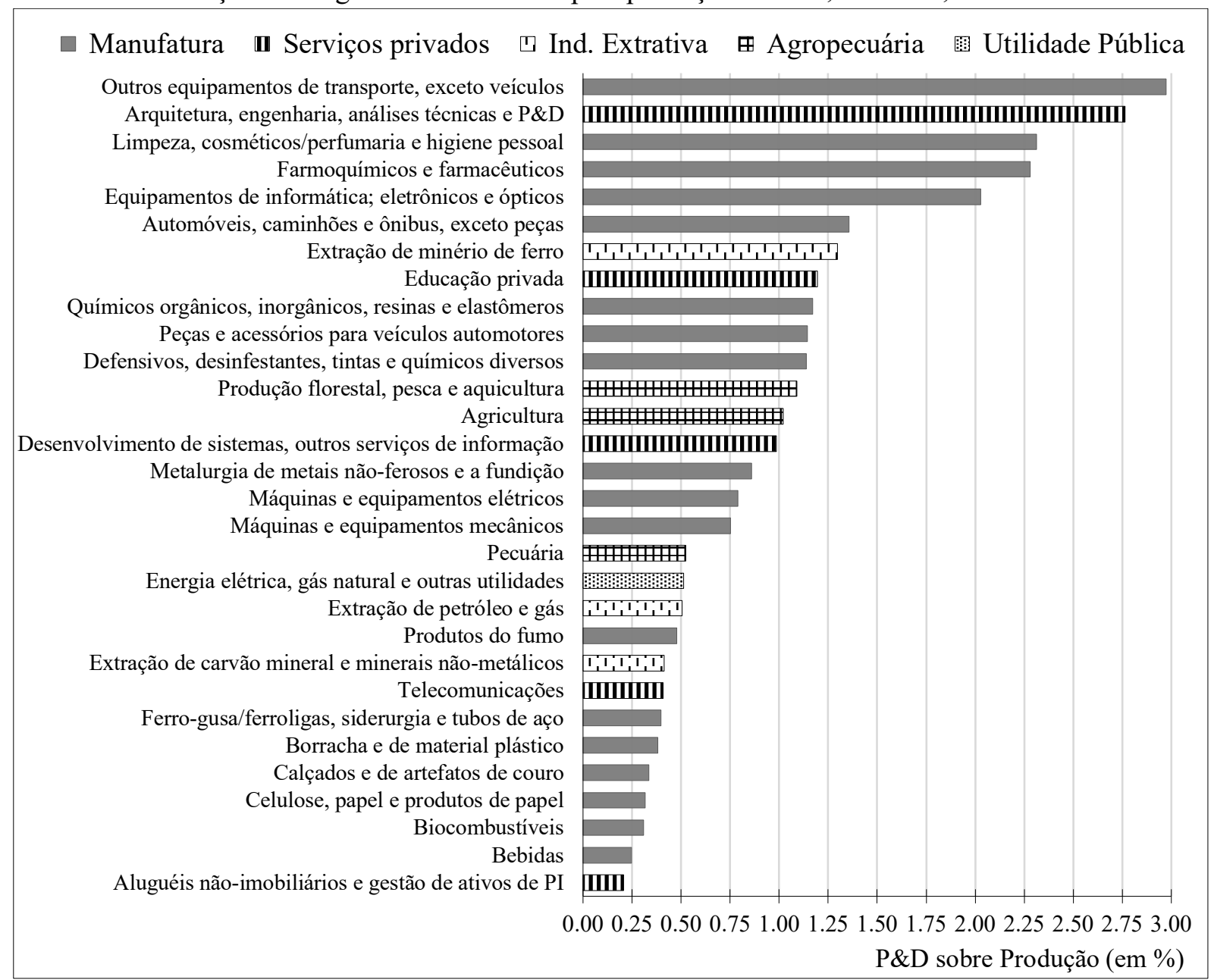

Nota: Todos os setores, exceto serviços públicos (Administração, Educação e Saúde pública).

Fonte: IBGE (2015a) e dados obtidos pela Lei de Acesso à Informação. Cálculos e elaboração do autor.

Os outros equipamentos de transportes possuem a maior intensidade em P\&D setorial, com aproximadamente 3,0\% do valor da produção investidos em P\&D. Esse setor reúne a produção de aviões, satélites, embarcações navais, motocicletas, veículos ferroviários e veículos militares de combate. No Brasil, as áreas da aviação, espacial e marinha possuem destaque nos investimentos em P\&D. Entre os principais centros de pesquisa destacam-se a $P \& D$ realizada pela Embraer, pelo Departamento de Ciência e Tecnologia Espacial (DCTA), pela Agência Espacial Brasileira (AEB) e pelo Centro Tecnológico da Marinha em São Paulo (CTMSP), que atualmente está envolvido no desenvolvimento do primeiro submarino de propulsão nuclear brasileiro. ${ }^{15}$

Entre os demais setores manufatureiros, lideram a lista produtos químicos; farmacêutica; informática e eletrônicos; e a automobilística, que também possuem média-alta e alta intensidade em P\&D

\footnotetext{
15 Todos os centros mencionados investiram mais de R\$ 100 milhões em P\&D, em 2013.
} 
em outros países (OECD, 2003, p. 157). Nos países líderes, os setores farmacêutico e de informática e eletrônicos lideram a classificação, mas no Brasil eles são muito dependentes de tecnologia importada embarcada nos insumos e componentes, conforme será visto na próxima seção.

Os serviços de arquitetura, engenharia, análises técnicas e $P \& D$ ocupam o segundo lugar em investimento em P\&D, com aproximadamente 2,75\% do valor da produção aplicados em P\&D. Como mencionado anteriormente, todos os departamentos de P\&D identificados com CNPJ próprio são classificados neste setor nas estatísticas das Contas Nacionais, independente da finalidade da pesquisa. Por isso, o esforço de P\&D é elevado, porém, cabe destacar que a maioria desses investimentos não está relacionada, necessariamente, com a descrição do setor arquitetura, engenharia, análises técnicas e $P \& D$.

Por fim, entre os 68 setores das contas nacionais, 25 são serviços privados mas apenas um quinto deles encontra-se exibido no Gráfico 1. A maioria dos serviços privados tem intensidade em P\&D muito baixa. As poucas exceções são a própria atividade de P\&D comentada no parágrafo anterior, educação privada e desenvolvimento e outros serviços de informação, os quais possuem investimentos em $\mathrm{P} \& \mathrm{D}$ sobre a produção superior à média da economia brasileira, de $0,54 \%$.

Cabe destacar que alguns setores tradicionais, como a extração de minérios de ferro e a agricultura, investiram em P\&D ligeiramente acima de 1,0\% do valor da produção. E a pecuária e a extração de petróleo e gás investiram $0,5 \%$, próximo à média da economia total. Como mencionado, nesses setores sobressai-se a P\&D realizada por IPP e por grandes empresas como a Petrobras e a Vale, contribuindo para manter o Brasil como um dos líderes globais na produção agropecuária e na indústria extrativa.

\section{P\&D incorporada na cadeia produtiva setorial e nos bens de investimento}

A seção anterior exibiu a $P \& D$ direta realizada pelos setores e esta identifica a $P \& D$ indireta que está incorporada nos insumos intermediários e nos bens de investimentos adquiridos pelos setores produtivos, que são uma forma importante de aquisição de conhecimento pelos setores usuários de tecnologias (PAPACONSTANTINOU; SAKURAI; WYCKOFF, 1998; PAVITT, 1984; ROSENBERG, 1982). Para Schmookler (1966, p. 175, tradução nossa) "a melhor maneira de melhorar a tecnologia de uma indústria é, muitas vezes, melhorar os insumos que ela compra de outras indústrias". Aghion e Howitt (1992) e Grossman e Helpman (1991) modelaram o progresso tecnológico pela introdução de inovações que melhoram a qualidade dos bens de capitais, os quais serão adquiridos para produzir bens finais. Além de expandir a capacidade produtiva, máquinas e equipamentos de última geração também aumentam a produtividade.

Cada vez mais, os produtos são sistêmicos e constituídos de muitos insumos e componentes que incorporam tecnologias de vários campos da ciência. Nas economias modernas, existe um alto grau de interdependências entre as atividades produtivas, sobretudo quanto às interdependências tecnológicas. Cabe destacar que muitas indústrias não produzem um produto final, mas sim insumos intermediários ou bens de capital que serão utilizados por outras indústrias, por exemplo, insumos da química e da biotecnologia, laminados de aço, componentes eletrônicos e softwares.

Ademais, o "uso de tecnologias incorporadas é uma característica tanto de firmas de média-alta e alta tecnologia como também de firmas de média-baixa e baixa tecnologia" (ROBERTSON; SMITH; VON TUNZELMANN, 2009, p. 445, tradução nossa). Assim, tanto o setor aeronáutico depende de tecnologia embarcada nos equipamentos eletrônicos quanto o setor têxtil depende das fibras químicas para produzir produtos melhores. $\mathrm{O}$ “(...) progresso tecnológico em um setor da economia tornou-se crescentemente dependente da mudança tecnológica em outros setores.” (ROSENBERG, 1982, p. 73, tradução nossa). Apesar de antiga, a passagem de Rosenberg tornou-se ainda mais importante na atualidade com a crescente fragmentação internacional da produção organizada em cadeias globais de valor.

Esta pesquisa rastreou os fluxos de P\&D ao levantar a intensidade em P\&D (P\&D/produção) do setor produtor dos insumos intermediários e dos bens de capital e multiplicá-la pelo valor da produção destinada os setores usuários. Desse modo, este trabalho adota as interdependências setoriais das matrizes de insumo-produto e de investimentos para captar as interdependências tecnológicas, conforme procedimentos metodológicos descritos na seção 3.4.2.

Por exemplo, a indústria aeronáutica investe diretamente montante elevado em $\mathrm{P} \& \mathrm{D}$, mas também a consome bastante indiretamente a partir dos produtos dos fornecedores de componentes (turbinas, motores 
e componentes eletrônicos) dos aviões. O método proposto por este trabalho rastreia essa P\&D indireta incorporada. Se o setor de informática investiu em P\&D 2,0\% do seu valor da produção, cada produto fabricado incorporou uma parte dessa $\mathrm{P} \& \mathrm{D}$ proporcional ao seu peso no valor da produção. Assim, quando o setor aeronáutico compra $5 \%$ da produção de informática, ele adquire insumos intermediários que incorporaram $0,10 \%$ da $P \& D$ realizada pelo setor de informática. Ao final, um avião possui tecnologia incorporada fruto da $\mathrm{P} \& \mathrm{D}$ direta da indústria aeronáutica e indireta contida na sua cadeia produtiva.

$\mathrm{Na}$ economia brasileira, a P\&D indireta correspondeu a $0,34 \%$ do valor da produção (Tabela 2 adiante). O Gráfico 3 exibe os 30 setores que têm maior P\&D indireta incorporada em suas cadeias produtivas. A maioria dos setores do Gráfico 3 faz parte da manufatura ou produzem bens físicos. Apenas os dois últimos setores são de serviços. Isso é esperado porque os setores manufatureiros possuem cadeias de produção mais longas e mais etapas de transformação produtiva, sobretudo em relação aos serviços. Exemplos disso são os três primeiros do Gráfico 3, que fabricam produtos (computadores, aviões e automóveis) compostos de centenas de insumos e componentes diferentes. Da mesma forma que eles possuem maiores multiplicadores de produção, suas cadeias produtivas carregam mais P\&D incorporada nos insumos intermediários.

Gráfico 3 - Percentual da P\&D incorporada na cadeia produtiva setorial em 2013

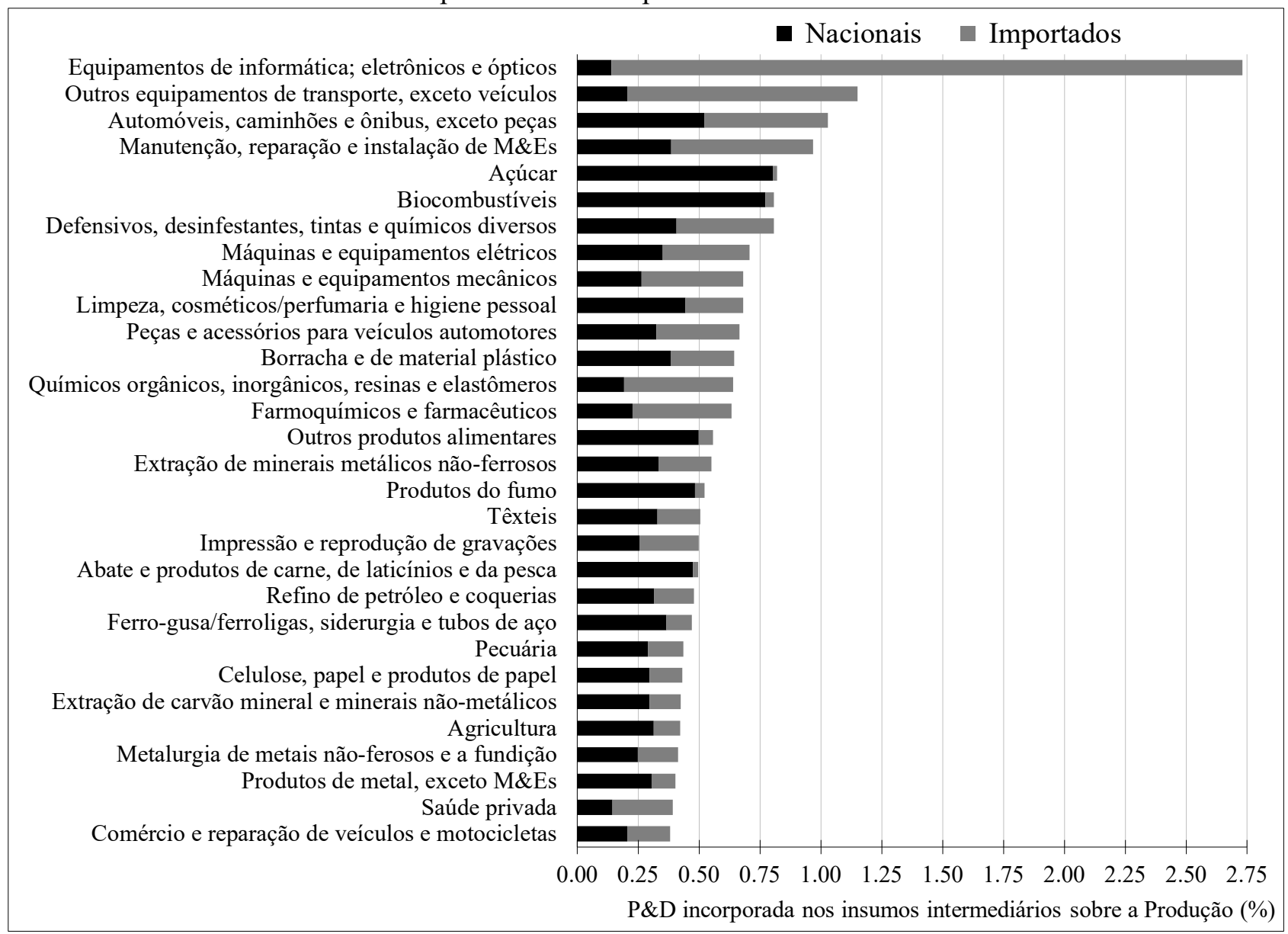

Fonte: IBGE (2015a), Guilhoto (2015), Galindo-Rueda e Verger (2016), BEA (2016) e Lei de Acesso à Informação. Cálculos e elaboração do autor.

Segundo ponto relevante é que, entre os 15 líderes, todos os dez setores manufatureiros de maior intensidade tecnológica dominam a lista (Gráfico 3). Além de fazer mais P\&D diretamente, eles também demandam insumos e componentes proporcionalmente mais intensivos em P\&D que a maioria dos setores de menor intensidade tecnológica. Observa-se também que a P\&D incorporada nos insumos intermediários importados é mais elevada para os setores de maior intensidade tecnológica do que nos setores menos intensivos. Isso confirma a dependência estrutural do Brasil por produtos mais tecnológicos no comércio internacional, conforme estudos sobre o comércio exterior brasileiro (IEDI, 2018; DE NEGRI, 2005). 
Terceiro, a P\&D da cadeia produtiva do setor de informática, eletrônicos e ópticos destaca-se bastante em relação aos demais setores ao somar 2,73\% do valor da produção desse setor (Gráfico 3). Esse é o único setor manufatureiro de maior intensidade tecnológica em que a P\&D da cadeia produtiva foi mais relevante que a $\mathrm{P} \& D$ realizada internamente. Ademais, da $\mathrm{P} \& \mathrm{D}$ embarcada nos insumos intermediários, 95\% são de origem estrangeira e apenas 5\% nacional (Gráfico 3). Isso explica-se porque i) o Brasil faz pouca $\mathrm{P} \& \mathrm{D}$ comparativamente ao realizado nesse setor pelos países líderes; ii) o setor importa parcela substantiva dos insumos intermediários, sobretudo componentes tecnológicos; e iii) esses componentes importados provêm majoritariamente do setor de informática e eletrônica, um dos que mais investe em $\mathrm{P} \& \mathrm{D}$ do planeta, que possui intensidade em $\mathrm{P} \& \mathrm{D}$ de $11,36 \%$ do valor da produção estrangeira. ${ }^{16} \mathrm{O}$ mesmo acontece, porém em menor magnitude, com os outros equipamentos de transporte que importam parcela expressiva dos componentes tecnológicos, principalmente turbinas e demais componentes dos aviões, os quais possuem elevada $P \& D$ embarcada.

Quarto, em muitos setores, a P\&D incorporada na cadeia produtiva é mais relevante que a própria P\&D realizada internamente. Em 19 dos vinte 20 setores manufatureiros de menor intensidade tecnológica, a P\&D da cadeia produtiva foi maior que a realizada internamente, assim como em 19 dos 25 setores de serviços privados. ${ }^{17}$ Do ponto de vista da atividade inovativa, esses setores são conhecidos como dominados pelos fornecedores pela tipologia de Pavitt (1984) e Castellacci (2008). Os setores dominados pelos fornecedores fazem pouca $\mathrm{P} \& \mathrm{D}$ interna e o progresso tecnológico relevante vem de fora, pois esses setores buscam reduzir custos produtivos através da adoção de máquinas e equipamentos (M\&Es) modernas que poupam mão de obra e de insumos intermediários mais eficientes (DOSI; PAVITT; SOETE, 1990, cap. 4).

A seguir, o Gráfico 4 mostra a P\&D embarcada nos investimentos fixos, que são constituídos majoritariamente por M\&Es e pela construção civil. O primeiro componente possui intensidade em $P \& D$ média-alta, enquanto o segundo praticamente não faz P\&D. Para contornar adversidades dos ciclos de negócios foi considerada a FBCF média do quadriênio 2010-2013. Para toda a economia brasileira, a P\&D incorporada nos investimentos fixos representou apenas $0,12 \%$ da sua produção (Tabela 2 adiante), percentual que corresponde apenas a um terço da P\&D incorporada nos insumos intermediários. Vale ressaltar que não foi considerado todo o estoque de capital, apenas o fluxo de FBCF médio de 2010-2013. Se fosse considerado todo o estoque de capital, provavelmente a P\&D incorporada seria maior que a dos insumos intermediários. Nota-se um perfil setorial mais diversificado no Gráfico 4. Dos 15 setores com maior P\&D incorporada nos investimentos fixos, 7 são de serviços, 4 da manufatura, 2 da agropecuária, 1 da indústria extrativa e 1 da utilidade pública.

Apesar de a indústria de transformação contribuir atualmente menos para a FBCF que no período de industrialização pesada (décadas de 1950 a 1980), ela ainda tem relevância significativa na P\&D embarcada nos bens de capital, haja vista que 16 dos 30 setores do Gráfico 4 são manufatureiros. Mesmo que a manufatura venha sofrendo um processo de desindustrialização desde a década de 1980, ela ainda detém percentual ligeiramente acima de um quarto do estoque de capital total do país ${ }^{18}$, desde 2008 até 2014 (GOUMA et al., 2018; TIMMER et al., 2016), o qual precisa ser constantemente atualizado para evitar a obsolescência dos equipamentos (via reposição do capital depreciado).

Ademais, na maioria dos setores a P\&D nacional é mais relevante que a importada como forma de adquirir tecnologia embarcada nos bens de capital (Gráfico 4). Entretanto, em alguns deles, a P\&D importada é um complemento relevante ou até mais importante que a nacional porque o Brasil não possui competitividade para produzir os bens de capital em todos segmentos produtivos.

Unindo todos os indicadores citados até o momento é possível estabelecer o multiplicador tecnológico calculado utilizando a P\&D total (direta e indireta) incorporada na produção anual de um setor dividido pela $\mathrm{P} \& \mathrm{D}$ conduzida diretamente pelo setor - ou seja, a intensidade em P\&D total dividida pela

\footnotetext{
${ }^{16}$ Informática e eletrônica é o setor que mais investe em P\&D entre os mil maiores gastos empresariais em P\&D do planeta, com 23,1\% do total investido, em 2017 (JARUZELSKI; STAACK; CHWALIK, 2017). Nos Estados Unidos, nação que mais investe em P\&D do mundo, esse setor realizou 21,0\% de toda a P\&D empresarial do país em média no período de 2010 a 2015 (OECDANBERD DATABASE, 2017).

${ }^{17}$ Dados não exibidos neste estudo devido à limitação de espaço. Para mais detalhes, ver estudo maior mencionado na nota 4 em que consta os dados de todos 68 setores da economia.

${ }^{18}$ Excluído o setor atividades imobiliárias (divisão 68 da CNAE 2.0).
} 
intensidade em P\&D direta. "Ele indica o nível de 'tecnologia' total incorporada na produção que é obtida a partir de R\$ 1,0 gasto em P\&D.” (PAPACONSTANTINOU; SAKURAI; WYCKOFF, 1996, p. 18, tradução nossa). ${ }^{19}$

Gráfico 4 - Percentual da P\&D incorporada na FBCF setorial, média 2010-2013

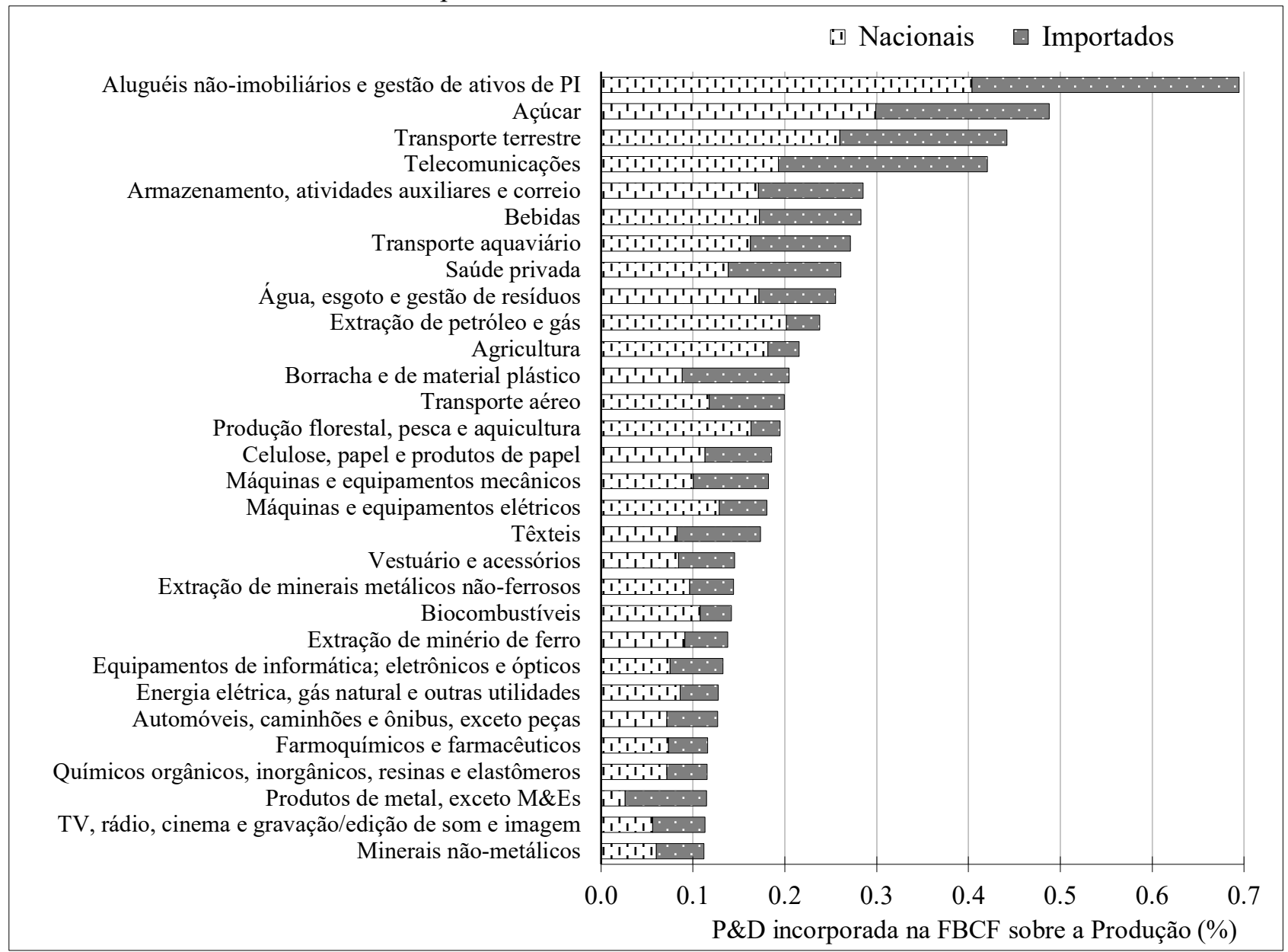

Fonte: IBGE (2015a), Miguez (2016), Galindo-Rueda e Verger (2016), BEA (2016) e dados obtidos pela Lei de Acesso à Informação. Cálculos e elaboração do autor.

O multiplicador tecnológico é semelhante aos multiplicadores de produção de Leontief, baseado no modelo output-to-output (MILLER; BLAIR, 2009, p. 283), isto é, o quanto se gera de produção total ${ }^{20}$ a partir de uma unidade de produção adicional de um setor específico. No entanto, no contexto deste trabalho, o multiplicador tecnológico reflete a natureza público-privada da tecnologia conforme mencionado por Papaconstantinou, Sakurai e Wyckoff (1996, p. 18, tradução nossa):

Está bem estabelecido que o conhecimento tem certas características típicas de bens públicos. É primeiro parcialmente excludente: é difícil para as empresas que fazem $P \& D$ se apropriarem plenamente dos benefícios econômicos por excluir outras empresas do seu uso. Também é não-rival: novas tecnologias podem ser usadas muitas vezes e em muitos processos diferentes sem ser exauridas.

A Tabela 2 exibe a intensidade em P\&D total fragmentada em seus cinco componentes e o multiplicador tecnológico para os principais agrupamentos setoriais. Para toda a economia, o multiplicador tecnológico foi de 1,9 (Tabela 2), dessa maneira, a intensidade em P\&D direta é quase a metade da intensidade em P\&D total. A literatura consultada também encontrou multiplicadores tecnológicos próximos de dois (HAUKNES; KNELL, 2009), principalmente para países grandes (PAPACONSTANTINOU; SAKURAI; WYCKOFF, 1996, p. 16). Variações no tamanho do multiplicador

19 Dietzenbacher e Los (2002) chamaram de "multiplicador de P\&D para trás" ao invés de multiplicador tecnológico e de "multiplicador de P\&D para trás induzido" para se referir apenas à P\&D indireta.

${ }^{20}$ Isto é, no produtor final, nos fornecedores de primeira ordem e nos fornecedores de ordem superior. 
refletem diferenças na estrutura industrial e no modo que cada setor cria e usa tecnologia. Setores produtivos que desenvolvem mais tecnologia internamente tem multiplicador próximo de 1,0, enquanto aqueles que usam mais tem multiplicador alto. Dessa maneira, o "[...] multiplicador tecnológico revela quais indústrias são produtoras de tecnologia e quais são usuárias de tecnologia.” (HAUKNES; KNELL, 2009, p. 464).

Tabela 2 - Multiplicador tecnológico por grupo de atividade

P\&D sobre a Produção (em \%)

Grupos de atividades econômicas

\begin{tabular}{|c|c|c|c|c|c|c|c|}
\hline \multirow[b]{2}{*}{ Grupos de atividades econômicas } & & \multirow[b]{2}{*}{$\begin{array}{l}\text { Multiplicador } \\
\text { Tecnológico }\end{array}$} \\
\hline & $\begin{array}{c}\text { Direta } \\
\text { (próprio } \\
\text { setor) }\end{array}$ & $\begin{array}{l}\text { Indireta } \\
\text { dos } \\
\text { insumos } \\
\text { nacionais }\end{array}$ & $\begin{array}{c}\text { Indireta } \\
\text { dos } \\
\text { insumos } \\
\text { importados }\end{array}$ & $\begin{array}{c}\text { Indireto } \\
\text { da } \\
\text { FBCF } \\
\text { nacional }\end{array}$ & $\begin{array}{c}\text { Indireto } \\
\text { da FBCF } \\
\text { importada }\end{array}$ & Total & \\
\hline Agropecuária & 0,89 & 0,29 & 0,11 & 0,15 & 0,03 & 1,47 & 1,7 \\
\hline Indústria Extrativa & 0,69 & 0,13 & 0,10 & 0,16 & 0,04 & 1,12 & 1,6 \\
\hline Indústria de transformação & 0,60 & 0,36 & 0,31 & 0,07 & 0,06 & 1,40 & 2,3 \\
\hline - De menor intensidade tecnológica & 0,20 & 0,38 & 0,12 & 0,07 & 0,06 & 0,82 & 4,2 \\
\hline - De maior intensidade tecnológica & 1,39 & 0,32 & 0,66 & 0,07 & 0,06 & 2,51 & 1,8 \\
\hline Eletricidade e gás, água, esgoto e limpeza urbana & 0,40 & 0,17 & 0,08 & 0,11 & 0,05 & 0,80 & 2,0 \\
\hline Construção & 0,02 & 0,22 & 0,09 & 0,05 & 0,04 & 0,41 & 25,9 \\
\hline Serviços & 0,54 & 0,12 & 0,06 & 0,05 & 0,05 & 0,82 & 1,5 \\
\hline - Privados & 0,14 & 0,12 & 0,06 & 0,06 & 0,05 & 0,43 & 3,1 \\
\hline - Públicos & 2,02 & 0,10 & 0,06 & 0,03 & 0,04 & 2,25 & 1,1 \\
\hline Economia total & 0,54 & 0,20 & 0,14 & 0,07 & 0,05 & 0,99 & 1,9 \\
\hline
\end{tabular}

Nota: No caso da FBCF utilizou-se a média de 2010-2013. Fonte: IBGE (2015a), Guilhoto (2015), Miguez (2016), GalindoRueda e Verger (2016), BEA (2016) e dados obtidos pela Lei de Acesso à Informação. Cálculos e elaboração do autor.

Os serviços públicos são quase um produtor puro de tecnologia ao dependerem praticamente da atividade de P\&D interna. Os setores manufatureiros de maior intensidade tecnológica, sobretudo os setores farmacêutico, outros equipamentos de transporte e segmentos químicos, possuem multiplicadores tecnológicos baixos por serem os principais produtores de tecnologia (Tabela 2). Quase todos os setores manufatureiros de menor intensidade tecnológica e dos serviços privados possuem multiplicadores tecnológicos elevados, sendo por isso grandes usuários de tecnologias produzidas por outros setores. Por esse motivo, a literatura os chama de dominados pelos fornecedores (CASTELLACCI, 2008; PAVITT, 1984) do ponto de vista inovativo, pois dependem de tecnologias incorporadas nos bens de investimento e nos insumos intermediários.

Chama atenção o fato de a agropecuária e a indústria extrativa não possuírem multiplicadores tecnológicos elevados. Geralmente, esses setores tradicionais são classificados como dominados pelos fornecedores de tecnologias (HAUKNES; KNELL, 2009; PAVITT, 1984), mas, no Brasil, a P\&D interna não é tão baixa devido ao apoio direto do Estado e indireto pela regulação.

Tabela $3-$ P\&D indireta total

\begin{tabular}{|c|c|c|c|c|c|}
\hline \multirow[b]{2}{*}{ Grupos das atividades econômicas } & \multirow{2}{*}{$\begin{array}{l}\text { P\&D indireta } \\
\text { total sobre a } \\
\text { Produção }(\%)\end{array}$} & \multicolumn{2}{|c|}{ P\&D indireta total $(\%)$} & \multicolumn{2}{|c|}{ P\&D indireta total $(\%)$} \\
\hline & & $\begin{array}{c}\text { Insumos } \\
\text { intermediários }\end{array}$ & $\begin{array}{c}\text { Bens de } \\
\text { capital }\end{array}$ & Nacional & Estrangeira \\
\hline Agropecuária & 0,59 & 69 & 31 & 76 & 24 \\
\hline Indústria Extrativa & 0,43 & 53 & 47 & 68 & 32 \\
\hline Indústria de transformação & 0,79 & 84 & 16 & 54 & 46 \\
\hline - De menor intensidade tecnológica & 0,63 & 80 & 20 & 71 & 29 \\
\hline - De maior intensidade tecnológica & 1,11 & 88 & 12 & 36 & 64 \\
\hline Eletricidade e gás, água, esgoto e limpeza urbana & 0,40 & 61 & 39 & 68 & 32 \\
\hline Construção & 0,40 & 78 & 22 & 68 & 32 \\
\hline Serviços & 0,28 & 64 & 36 & 60 & 40 \\
\hline - Privados & 0,29 & 63 & 37 & 61 & 39 \\
\hline - Públicos & 0,23 & 68 & 32 & 59 & 41 \\
\hline Economia total & 0,46 & 74 & 26 & 59 & 41 \\
\hline
\end{tabular}

Nota: No caso da FBCF utilizou-se a média de 2010-2013. Fonte: IBGE (2015a), Guilhoto (2015), Miguez (2016), Galindo-

Rueda e Verger (2016), BEA (2016) e dados obtidos pela Lei de Acesso à Informação. Cálculos e elaboração do autor. 
Em resumo, a P\&D indireta incorporada nas M\&Es e nos insumos intermediários é uma forma relevante para adquirir tecnologia, tanto para os setores que fazem pouco esforço tecnológico internamente quanto para aqueles de alta tecnologia. Para toda a economia brasileira, a P\&D indireta representou $0,46 \%$ da produção total (Tabela 3). A indústria de transformação possui relativamente mais P\&D indireta incorporada na produção que os demais setores, enquanto os serviços possuem menos. Contribui para isso o fato de a manufatura ter cadeias produtivas longas e os serviços curtas. No Brasil, os insumos intermediários são a principal fonte de aquisição de tecnologia externa para todos os agrupamentos setoriais da Tabela 3, chegando a representar três quartos da P\&D indireta total, enquanto os bens de capital tiveram um peso relativamente menor, inclusive para o setor de serviços, em comparação com os países desenvolvidos estudados por Papaconstantinou, Sakurai e Wyckoff (1998) e Hauknes e Knell (2009). Certamente, a baixa taxa de investimento do país contribui para esse resultado.

Quanto à origem da P\&D indireta, aproximadamente 60\% é nacional e 40\% estrangeira. Apesar de o país importar os principais produtos tecnológicos, a maioria das compras setoriais provém de fornecedores nacionais de menor P\&D incorporada, sobretudo porque a estrutura produtiva brasileira é concentrada em setores tradicionais que fazem relativamente pouca P\&D. Apenas para manufatura de maior intensidade tecnológica, a P\&D estrangeira é maior que a nacional. Nesse caso, o Brasil comporta-se como um país pequeno e é dependente de tecnologia externa, diferente do ocorrido nos países desenvolvidos grandes, conforme mencionado na revisão bibliográfica. No geral, o Brasil comporta-se como país grande, porém, como pequeno, no que se refere aos setores manufatureiros de maior intensidade tecnológica, porque importa os principais componentes tecnológicos.

\section{Considerações finais}

A pesquisa e desenvolvimento $(\mathrm{P} \& \mathrm{D})$ é uma das principais formas utilizadas, sobretudo nos países desenvolvidos, para promover o progresso tecnológico. Nos países em desenvolvimento, além da P\&D interna, a P\&D indireta incorporada nos insumos intermediários e nos bens de capital é uma forma importante de adquirir conhecimento tecnológico para elevar a produtividade. Apesar de ser difícil mensurar a P\&D indireta devido à disponibilidade de dados, este estudo conseguiu superar essa dificuldade.

Esta pesquisa adotou uma metodologia inovadora a partir de três etapas para captar a P\&D pública e privada de todos os 68 setores de atividade da economia brasileira, desde a agricultura até os serviços. A primeira etapa buscou criar um método para captar os investimentos em P\&D realizados pelos setores de atividades das novas Contas Nacionais do Brasil, o qual pode ser replicado para obter os investimentos em $\mathrm{P} \& \mathrm{D}$ setoriais à medida que as contas nacionais anuais forem divulgadas. A novidade metodológica da segunda etapa consistiu em identificar o volume de $\mathrm{P} \& \mathrm{D}$ realizado por institutos públicos de pesquisa a partir de dezenas de solicitações de dados no âmbito da Lei de Acesso à Informação. A partir disso, foi adotada uma estratégia para alocar a $P \& D$ pública em seus respectivos setores de atividade de acordo com a finalidade setorial das pesquisas de cada instituto. Com isso encontrou-se que no Brasil a P\&D pública é muito relevante para o desenvolvimento tecnológico de vários setores de atividade e que o setor privado beneficia-se dos resultados de pesquisas geradas em institutos públicos reconhecidos. A terceira etapa combinou dados das contas nacionais, das matrizes de insumo-produto e de absorção de investimentos e do indicador de esforço tecnológico ( $\mathrm{P} \& \mathrm{D} /$ produção) nacional e estrangeiro para obter a $\mathrm{P} \& \mathrm{D}$ indireta incorporada nos insumos intermediários e nos bens de investimento nacionais e importados para 68 setores produtivos da economia brasileira, sendo o estudo setorial de P\&D indireta mais detalhado. Para isso, foi utilizada uma metodologia consagrada internacionalmente de análise de insumo-produto. O diferencial deste estudo encontra-se no tratamento dos dados a partir de diversas fontes de informações e no nível setorial bem detalhado, sendo que para alguns setores produtivos as informações de P\&D são inéditas para o Brasil. Foi verificado que existe uma grande heterogeneidade setorial tanto na produção quanto no uso da P\&D. A seguir, apresentam-se as demais conclusões.

Primeiro, o Estado brasileiro tem um papel muito importante nos investimentos em P\&D direta e indiretamente. Diretamente investe percentual um pouco superior a 50\% da P\&D total do país. Apenas a educação pública investe quase um terço da $\mathrm{P} \& \mathrm{D}$ total com ações voltadas à pesquisa universitária $\mathrm{e}$ treinamento, e, embora essa $\mathrm{P} \& \mathrm{D}$ tenha menor aplicação comercial, ela sustenta a formação de recursos humanos qualificados para atuar no setor privado e desenvolver pesquisas em qualquer área. A pesquisa 
realizada por institutos públicos destaca-se principalmente nos setores agropecuário, mineração, aviação e espacial, naval, energia, informática, além do setor de saúde pública. Indiretamente, o Estado estimula a P\&D com financiamentos reembolsáveis e subvenções, e através de regulações setoriais exigindo contrapartidas na forma de $\mathrm{P} \& \mathrm{D}$ no setor de extração de petróleo e gás natural, energia elétrica e informática e eletrônica. Além disso, o Estado possui atuação ativa no conselho administrativo de empresas de capital misto ou pela golden share em empresas relevantes no contexto da P\&D nacional, como Petrobras, Vale e Embraer. Isso ajuda a explicar as áreas em que o país é competitivo internacionalmente, especialmente nos setores baseados em recursos naturais (agropecuária, mineração e petróleo) e na produção de aviões.

Segundo, a P\&D indireta incorporada nos insumos intermediários e nos bens de investimento é uma fonte muito relevante de aquisição de tecnologia tanto para os setores que fazem pouca P\&D (dominado pelos fornecedores) quanto para os que realizam muita P\&D (baseados em ciência). Para os setores manufatureiros de menor intensidade tecnológica e para a maioria dos serviços privados, a P\&D indireta foi mais relevante que a realizada diretamente. No caso dos setores manufatureiros de maior intensidade tecnológica, principalmente a P\&D indireta incorporada nos insumos e componentes tecnológicos importados foi muito relevante, em especial para o setor de informática, eletrônicos e ópticos. A dependência tecnológica do exterior, geralmente diagnosticada nos estudos de comércio exterior, também foi capturada aqui e evidenciada pela elevada importação de insumos e componentes intensivos em P\&D.

Terceiro, a P\&D indireta incorporada nos bens de investimento é muito baixa, inclusive no setor de serviços, que costuma depender mais dos bens de capital que dos insumos intermediários para adquirir conhecimento tecnológico. A baixa taxa de investimento brasileira corrobora esse resultado, somado ao fato de os setores nacionais produtores de bens de capital possuírem intensidade em P\&D relativamente baixa se comparada à fronteira tecnológica.

Quarto, os setores de serviços privados fazem pouca P\&D direta, com exceção de dois segmentos de serviços intensivos em conhecimento. Do ponto de vista de geração de tecnologia, a mudança estrutural prematura da economia brasileira em direção ao setor de serviços é muito preocupante, haja vista que a manufatura é composta pelos setores que mais realizam $\mathrm{P} \& \mathrm{D}$, mesmo quando considerada a manufatura tradicional (de baixa e média-baixa tecnologia).

Os formuladores de políticas poderiam fomentar a atividade de P\&D no Brasil ao fortalecer os institutos públicos de pesquisa e manter a estabilidade no provisionamento de recursos para manter e/ou melhorar o desempenho tecnológico nas áreas de interesse nacional em que esses institutos atuam. O Estado poderia também estimular a parceria entre as universidades e empresas com vistas a desenvolver pesquisas em áreas de grande interesse nacional e de múltiplas aplicações produtivas, pois a colaboração entre as universidades e o setor privado ainda é fraca no Brasil. As universidades também deveriam focar na produção e comercialização de inovações e não se restringir à produção científica e ensino.

Como visto o Brasil tem uma grande dependência do exterior de insumos intermediários intensivos em P\&D. Para diminuir um pouco essa dependência o Estado poderia escolher algumas poucas áreas em que há mais chances de o país ser competitivo e conceder incentivos e exigir contrapartidas de P\&D. É importante que haja focalização em poucos segmentos produtivos porque as áreas tecnológicas necessitam de um volume expressivo de recursos para competir na fronteira tecnológica.

Conforme essa pesquisa mensurou, a P\&D indireta incorporada nos produtos importados é uma fonte significativa de absorção tecnológica. O Brasil poderia firmar acordos bilaterais de comércio com países relevantes na sua pauta comercial com a finalidade de baratear as importações de insumos e bens de capital e tornar as exportações domésticas mais competitivas no mercado estrangeiro.

Além disso, para o desenvolvimento tecnológico aumentar de forma sustentada o custo para se fazer negócios no Brasil deve ser reduzido e as instituições nacionais precisam ser fortalecidas para assegurarem a estabilidade política e econômica, de modo que a incerteza diminua. A burocracia precisa ser substantivamente reduzida pela modernização dos órgãos reguladores e simplificação dos processos tributários e legais. Além disso, a legislação do país precisa ser revista a fimm de diminuir a corrupção.

Essas sugestões de políticas podem aumentar a P\&D nacional, atualizar os meios de produção e produzir inovações para as empresas domésticas aumentarem sua competitividade. 


\section{Referências}

AGHION, P.; HOWITT, P. A model of growth through creative destruction. Econometrica, v. 60, n. 2, 1992.

BEA - BUREAU OF ECONOMIC ANALYSIS. U.S. input-output accounts: 1997-2015. Washington, DC: U.S. Department of Commerce, 2016.

BRESCHI, S.; MALERBA, F. Sectoral innovation systems: technological regimes, Schumpeterian dynamics, and spatial boundaries. In: EDQUIST, C. (Org.). . Systems of innovation: technologies, institutions and organizations. Abingdon: Routledge, 1997.

CASTELLACCI, F. Technological paradigms, regimes and trajectories: manufacturing and service industries in a new taxonomy of sectoral patterns of innovation. Research Policy, v. 37, n. 6-7, 2008.

COHEN, W. M.; LEVINTHAL, D. A. Innovation and learning: the two faces of R\&D. The Economic Journal, v. 99, n. 397, 1989.

DE NEGRI, F. Conteúdo tecnológico do comércio exterior brasileiro: o papel das empresas estrangeiras. , Texto para Discussão do IPEA No. 1074. Brasília: IPEA, 2005.

DE NEGRI, J. A.; SALERNO, M. S. (Org.). Inovações, padrões tecnológicos e desempenho das firmas industriais brasileiras. Brasília: IPEA, 2005.

DIETZENBACHER, E.; LOS, B. Externalities of R\&D expenditures. Economic Systems Research, v. 14, n. 4, 2002.

DOSI, G.; PAVITT, K.; SOETE, L. The economics of technical change and international trade. New York: New York University Press, 1990.

EVANGELISTA, R. Sectoral patterns of technological change in services. Economics of Innovation and New Technology, v. 9, n. 3, 2000.

FURTADO, A. T.; CARVALHO, R. D. Q. Padrões de intensidade tecnológica da indústria brasileira: um estudo comparativo com os países centrais. São Paulo em Perspectiva, v. 19, n. 1, 2005.

GALINDO-RUEDA, F.; VERGER, F. OECD taxonomy of economic activities based on R\&D intensity. , OECD Science, Technology and Industry Working Papers No. 2016/04. Paris: OECD, 2016.

GOUMA, R. et al. WIOD socio-economic accounts 2016: sources and methods. Groningen: WIOD, 2018.

GROSSMAN, G. M.; HELPMAN, E. Innovation and growth in the global economy. Cambridge, MA: The MIT Press, 1991.

GUILHOTO, J. J. M. Sistema de matrizes de insumo-produto para o Brasil 2013 - 68 setores. São Paulo: NEREUS, 2015.

GUILHOTO, J. J. M.; SESSO FILHO, U. A. Estimação da matriz insumo-produto a partir de dados preliminares das contas nacionais. Economia Aplicada, v. 9, n. 2, 2005.

GUILHOTO, J. J. M.; SESSO FILHO, U. A. Estimação da matriz insumo-produto utilizando dados preliminares das contas nacionais: aplicação e análise de indicadores econômicos para o Brasil em 2005. Economia \& Tecnologia, v. 23, 2010.

HATZICHRONOGLOU, T. Revision of the high-technology sector and product classification. , OECD Science, Technology and Industry Working Papers No. 1997/02. Paris: OECD Publishing, 1997.

HAUKNES, J.; KNELL, M. Embodied knowledge and sectoral linkages: an input-output approach to the interaction of high- and low-tech industries. Research Policy, v. 38, n. 3, 2009.

HIPP, C.; GRUPP, H. Innovation in the service sector: the demand for service-specific innovation measurement concepts and typologies. Research Policy, v. 34, n. 4, 2005.

IBGE. Nota metodológica $n^{\circ}$ 16: pesquisa e desenvolvimento (versão para informação e comentários). Rio de Janeiro: Coordenação de Contas Nacionais, IBGE, 2015a

IBGE. A. Sistema de contas nacionais: Brasil: 2010-2013. Rio de Janeiro: IBGE, 2015b.

IEDI. Indústria de transformação por intensidade tecnológica em 2017: aumento generalizado de exportações e importações. Carta IEDI No. 830. São Paulo: IEDI, 2018.

JARUZELSKI, B.; STAACK, V.; CHWALIK, R. The global innovation 1000: will stronger borders weaken innovation? strategy+business, n. 89 (winter), p. 16, 2017.

JARUZELSKI, B.; STAACK, V.; SHINOZAKI, A. Global innovation 1000: software-as-a-catalyst. strategy+business, n. 85 (winter), p. 16, 2016. 
KER, D.; GALINDO-RUEDA, F. Frascati manual $R \& D$ and the system of national accounts., OECD Science, Technology and Industry Working Papers No. 2017/06. Paris: OECD Publishing, 2017.

LALL, S. The technological structure and performance of developing country manufactured exports, 198598. Oxford Development Studies, v. 28, n. 3, 2000.

MCTI - MINISTÉRIO DA CIÊNCIA E TECNOLOGIA. Metodologia e critérios para levantamento dos investimentos nacionais em ciência e tecnologia (Relatório Técnico). Brasília: MCTI, 2009.

MIGUEZ, T. DE H. L. Evolução da formação bruta de capital fixo na economia brasileira 2000-2013: uma análise multissetorial a partir das matrizes de absorção de investimento (MAIs). $155 \mathrm{f}$. Tese (Doutorado) - Instituto de Economia, Universidade Federal do Rio de Janeiro, Rio de Janeiro, 2016.

MILLER, R. E.; BLAIR, P. D. Input-output analysis: foundations and extensions. 2. ed. Cambridge: Cambridge University Press, 2009.

OCDE. Oslo manual: guidelines for collecting and interpreting innovation data. 3. ed. Paris: OECD: Eurostat, 2005.

OECD. Frascati Manual 2015: guidelines for collecting and reporting data on research and experimental development. Paris: OECD Publishing, 2015.

OECD. OECD science, technology and industry scoreboard 2003. Paris: OECD Publications, 2003.

OECD-ANBERD DATABASE. Analytical business enterprise research and development database ANBERD (ISIC Rev. 4). Paris: OECD, 2017. Disponível em: <http://oe.cd/anberd>.

PAPACONSTANTINOU, G.; SAKURAI, N.; WYCKOFF, A. Domestic and international productembodied R\&D diffusion. Research Policy, v. 27, n. 3, 1998.

PAPACONSTANTINOU, G.; SAKURAI, N.; WYCKOFF, A. Embodied technology diffusion: an empirical analysis for 10 OECD countries. OECD Science, Technology and Industry Working Papers No. 1996/01. Paris: OECD Publishing, 1996.

PAVITT, K. Sectoral patterns of technical change: towards a taxonomy and a theory. Research Policy, v. 13, n. 6, 1984.

PINTEC. Pesquisa de inovação: 2014. Rio de Janeiro: IBGE, Coordenação de Indústria, 2016.

ROBERTSON, P.; SMITH, K.; VON TUNZELMANN, N. Innovation in low- and medium-technology industries. Research Policy, v. 38, n. 3, 2009.

ROSENBERG, N. Technological interdependence in the American economy. Inside the black box: technology and economics. Cambridge: Cambridge University Press, 1982.

SABATO, J. A. El comercio de tecnologia. Ensayos en campera. Buenos Aires: Juarez Editor, 1979.

SCHERER, F. M. Inter-industry technology flows in the United States. Research Policy, v. 11, n. 4, 1982.

SCHMOOKLER, J. Invention and economic growth. Cambridge, Massachusetts: Harvard University Press, 1966.

SCHUMPETER, J. A. Capitalism, socialism and democracy. New York: Harper \& Brothers, 1942.

SCHUMPETER, J. A. The theory of economic development. Cambridge, Massachusetts: Harvard University, 1934.

SNA 2008. System of national accounts 2008. New York: United Nations; European Comission; Organisation for Economic Co-operation and Development; International Monetary Fund; Bank World, 2009.

TERLECKYJ, N. J. Effects of R\&D on the productivity growth of industries: an exploratory study. Washington, DC: National Planning Association, 1974.

TIMMER, M. P. et al. An anatomy of the global trade slowdown based on the WIOD 2016 release. GGDC Research Memorandum No. 162. Groningen: Groningen Growth and Development Centre, 2016. 


\section{Apêndice A: Alocação da P\&D dos institutos públicos de pesquisa e da Petrobras nos setores de atividade de finalidade da pesquisa}

Tabela A.1 - Alocação setorial da P\&D dos institutos públicos de pesquisa, 2013 (R\$ de 2017) ${ }^{21}$

\begin{tabular}{|c|c|c|}
\hline Instituto Público de Pesquisa & Setor de atividade da pesquisa no SCN Ref. 2010 & Valor \\
\hline Embrapa - Empresa Brasileira de Pesquisa Agropecuária & \multirow[b]{2}{*}{ - Agricultura: $76,1 \%$} & $3.252,9$ \\
\hline $\begin{array}{l}\text { EPAGRI - Empresa de Pesquisa Agropecuária e Extensão Rural de Santa } \\
\text { Catarina }\end{array}$ & & 368,6 \\
\hline APTA - Agência Paulista de Tecnologia dos Agronegócios, exceto ITAL & \multirow{5}{*}{$\begin{array}{l}\text { - Pecuária: } 17,0 \% \\
\text { - Produção florestal, pesca e aquicultura: } 6,9 \%\end{array}$} & 243,9 \\
\hline $\begin{array}{l}\text { BAHIATER - Superintendência Baiana de Assistência Técnica e Extensão } \\
\text { Rural (antiga EBDA - Empresa Baiana de Desenvolvimento Agrícola) }\end{array}$ & & 195,3 \\
\hline IAPAR - Instituto Agronômico do Paraná & & 147,1 \\
\hline EPAMIG - Empresa de Pesquisa Agropecuária de Minas Gerais & & 111,3 \\
\hline Outros institutos agropecuários estaduais $* *$ & & 311,5 \\
\hline CPRM - Companhia de Pesquisa de Recursos Minerais & \multirow{2}{*}{$\begin{array}{l}\text { Extração de minério de ferro }(83,1 \%) \text {; extração de } \\
\text { carvão mineral e minerais não-metálicos }(13,7 \%) \text {; e } \\
\text { extração de minerais metálicos não-ferrosos }(3,1 \%)\end{array}$} & 672,4 \\
\hline CETEM - Centro de Tecnologia Mineral & & 45,1 \\
\hline CNEN - Comissão Nacional de Energia Nuclear & Energia elétrica, gás natural e outras utilidades & 346,1 \\
\hline DCTA - Departamento de Ciência e Tecnologia Aeroespacial & Outros equipamentos de transporte, exceto veículos & 335,0 \\
\hline AEB - Agência Espacial Brasileira & Outros equipamentos de transporte, exceto veículos & 299,8 \\
\hline CTMSP - Centro Tecnológico da Marinha em São Paulo & Outros equipamentos de transporte, exceto veículos & 172,5 \\
\hline CEITEC - Centro de Excelência em Tecnologia Eletrônica Avançada & Equipamentos de informática; eletrônicos e ópticos & 137,7 \\
\hline Instituto Butantan & Saúde pública & 75,1 \\
\hline Instituto Vital Brazil do Rio de Janeiro & Saúde pública & 65,2 \\
\hline Instituto Adolfo Lutz de SP* & Saúde pública & 64,5 \\
\hline IPqM - Instituto de Pesquisas da Marinha & Outros equipamentos de transporte, exceto veículos & 53,8 \\
\hline Instituto Florestal de SP* & Produção florestal, pesca e aquicultura & 50,5 \\
\hline ITAL - Instituto de Tecnologia de Alimentos da APTA & $\begin{array}{l}\text { Outros produtos alimentares }(47,2 \%) \text {; abate e } \\
\text { produtos de carne, de laticínios e da pesca }(32,7 \%) \text {; } \\
\text { Bebidas }(20,1 \%)\end{array}$ & 49,9 \\
\hline LNLS - Laboratório Nacional de Luz Síncrotron do CNPEM & Equipamentos de informática; eletrônicos e ópticos & 46,4 \\
\hline Instituto de Botânica de SP* & Produção florestal, pesca e aquicultura & 42,0 \\
\hline $\begin{array}{l}\text { CTBE - Laboratório Nacional de Ciência e Tecnologia do Bioetanol do } \\
\text { CNPEM }\end{array}$ & Biocombustíveis & 36,6 \\
\hline CASNAV - Centro de Análises de Sistemas Navais & Outros equipamentos de transporte, exceto veículos & 32,6 \\
\hline CTI - Centro de Tecnologia da Informação Renato Archer & Equipamentos de informática; eletrônicos e ópticos & 30,6 \\
\hline LNNano - Laboratório Nacional de Nanotecnologia do CNPEM & $\begin{array}{l}\text { Químicos orgânicos, inorgânicos, resinas e } \\
\text { elastômeros }\end{array}$ & 28,2 \\
\hline LNBio - Laboratório Nacional de Biociências do CNPEM & Farmoquímicos e farmacêuticos & 28,1 \\
\hline CTEx - Centro Tecnológico do Exército & Produtos de metal, exceto M\&Es & 23,2 \\
\hline Instituto Pasteur e demais Institutos de Saúde de SP* & Saúde pública & 16,9 \\
\hline LNCC - Laboratório Nacional de Computação Científica & Equipamentos de informática; eletrônicos e ópticos & 4,4 \\
\hline Total & & $7.287,5$ \\
\hline
\end{tabular}

Nota: Deflator implícito do PIB. *Estimado a partir do $\mathrm{n}^{\mathrm{o}}$ de pesquisadores do instituto multiplicado pelos investimentos em P\&D por pesquisador realizado pela APTA. **Onze instituições agropecuárias estaduais menores em montante de P\&D. Fonte: Dados recebidos dos próprios institutos no âmbito da Lei de Acesso à Informação, dos Portais da Transparência Estaduais e Indicadores Estaduais de Ciência \& Tecnologia - 2013 do MCTI. Elaborado pelo autor.

Tabela A.2 - Alocação setorial dos investimentos em P\&D do CENPES-Petrobras

\begin{tabular}{lrr}
\hline Setor de atividade do SCN Ref. 2010 & Distribuição em \% & P\&D de 2013 (em RS de 2017) \\
\hline Extração de petróleo e gás & 59,7 & $1.211,5$ \\
\hline Refino de petróleo e coquerias & 21,5 & 436,5 \\
\hline Biocombustíveis & 4,6 & 93,4 \\
\hline Energia elétrica, gás natural e outras utilidades & 14,2 & 289,3 \\
\hline Total & $\mathbf{1 0 0 , 0}$ & $\mathbf{2 . 0 3 0 , 7}$ \\
\hline
\end{tabular}

Nota: Deflator implícito do PIB. Fonte: Dados de despesas em P\&D por área recebidos da Petrobras pela Lei de Acesso à Informação e descrição das despesas por ação em 2013. Elaborado pelo autor.

${ }^{21}$ A Fundação Oswaldo Cruz (Fiocruz) não está exibida na Tabela A.1 porque já se encontra alocada no setor de saúde pública no SCN Ref. 2010. Em 2013, a Fiocruz investiu em P\&D R\$ 1.409,6 milhões de 2017, sendo a terceira instituição que mais investiu em pesquisa no Brasil, atrás apenas da Embrapa e da Petrobras. 